\title{
Introducción al Geopatrimonio kárstico del municipio de El Peñón (Santander), Colombia
}

\author{
Jorge Gelvez-Chaparroㅜㄹ Daniel Barajas-Rangel ${ }^{1}$; Juliana Herrera-Ruiz ${ }^{1}$; Carlos Alberto Ríos-Reyes ${ }^{1 *}$
}

doi: https://doi.org/10.18273/revbol.v42n2-2020008 (c) (1)

Forma de citar: Gelvez-Chaparro, J.; Barajas-Rangel, D.; Herrera-Ruiz, J.; Ríos-Reyes, C.A. (2020). Introducción al Geopatrimonio kárstico del municipio de El Peñón (Santander), Colombia. Boletín de Geología, 42(2), 147-167. doi: 10.18273/revbol.v42n2-2020008.

\section{Resumen}

Los sistemas kársticos constituyen uno de los ambientes más vulnerables al cambio climático y las acciones humanas, así mismo las actividades turísticas mal desarrolladas en áreas con sistemas kársticos (espeleoturismo) han demostrado que pueden ser una amenaza para su conservación, sin embargo, el turismo también podría ser una forma efectiva de conservación aportando a su vez al desarrollo sostenible de los territorios rurales. El municipio más joven de Santander, El Peñón, ubicado sobre rocas calcáreas de la Formación Rosablanca constituye un extenso e importante sistema kárstico que alberga una gran riqueza geológica, paisajística, arqueológica y biótica. El desarrollo kárstico de la región está regido por el control tectónico de la zona evidenciado en las orientaciones preferenciales NW-SE y NE-SW que adquieren las unidades exo y endokársticas. El estado casi prístino de la gran mayoría de estas manifestaciones subterráneas permite su estudio para la contribución al planteamiento de alternativas que vean este patrimonio como un recurso con gran potencial para aportarle al desarrollo sostenible de este territorio.

Se presentan avances en el inventario del patrimonio geológico kárstico con el que cuenta el municipio de El Peñón, y la valoración por medio de la metodología M-GAM de los primeros 6 geotopos identificados: Cañón de Panamá, Caverna Los Carracos, Cueva del Oro, Cueva de La Virgen, Karst Town y Caverna La Tronera. La evaluación por medio de esta metodología permitió conocer la situación actual del turismo en la región y confirmar que estos lugares poseen una riqueza única con vastas oportunidades para el desarrollo del geoturismo y espeleoturismo. La aplicación del índice estandarizado de sensibilidad de cuevas permitió conocer el grado de sensibilidad a las acciones antrópicas de estos ecosistemas, indicando el mayor control que debe existir sobre las actividades que se desarrollen en la galería inferior de la Caverna Los Carracos y la Cueva del Oro.

Palabras clave: Karst; Geoturismo; Espeleoturismo; Cueva.

\section{Introduction to the Karst Geoheritage of the municipality of El Peñón (Santander, Colombia)}

\begin{abstract}
Karstic systems constitute one of the most vulnerable environments to climate change and human actions, the tourist activities not suitables in areas with karstic systems (speleotourism) have shown that it can be a danger to their conservation, nevertheless, tourism could also be an effective way of conservation contributing to the sustainable development of rural territories. The youngest municipality in Santander, El Peñón, located on calcareous rocks of the Rosablanca Formation constitutes an extensive and important karstic system that houses a great geological, landscape, archeological and biotic wealth. The karstic development of the region is governed by the tectonic control of the area evidenced in the preferential orientations NW-SE and NE-SW acquired by the exo and endo karst units. The almost pristine state of the great majority of these underground manifestations allows its study for the contribution to the approach of alternatives that see this heritage as a resource with great potential to contribute to the sustainable development of this territory with a recent past of violence.

Advances are made in the inventory of the karstic geological heritage that El Peñón has, and the valuation through the M-GAM methodology of the first 6 identified geosites: Panama canyon, Los Carracos Cavern, Golden Cave, Virgin's Cave, Karst Town and La Tronera Cavern. The evaluation through this methodology allowed an evaluation of tourism in the region and confirm that these places have a unique wealth with vast opportunities for the development of geotourism and speleotourism. The application of the standardized index of sensitivity of caves also allowed us to have a better understanding of the richness of these ecosystems, indicating the greater control that should exist over human activities that take place in the lower gallery of Los Carracos Cavern and Golden Cave.
\end{abstract}

Keywords: Karst; Geotourism; Speleotourism; Cave.

${ }^{1}$ Semillero de Investigación en Patrimonio Geológico, Grupode Investigaciónen Geología Básica y Aplicada, Escuela de Geología, Universidad Industrial de Santander, Bucaramanga, Colombia. jorgeegelvez96@hotmail.com;dsbarajas14@gmail.com; juliana.herrera9314@gmail.com; (*) carios@uis.edu.co 


\section{Introducción}

El estudio de la geodiversidad y el patrimonio geológico de los territorios es una de las áreas de investigación más jóvenes dentro de las Geociencias, solo en algunos países pioneros como Gran Bretaña se inició a mediados del siglo XX, y surgió a partir de la concientización de ver los elementos geológicos de singular interés (Patrimonio Geológico) como un recurso no renovable que puede aportar de manera significativa al desarrollo sostenible de las zonas rurales principalmente (Carcavilla-Urquí et al., 2007, 2016; Palacio-Prieto et al., 2016). El patrimonio geológico y el geoturismo son interdependientes, el patrimonio necesita ser valorado por toda la comunidad en general, para lo cual el turismo puede ser una forma efectiva de extender la importancia del patrimonio como un componente valioso del mundo natural que una vez identificado necesita ser protegido (Newsome y Dowling, 2018).

En Colombia el patrimonio geológico se estudia desde los años ochenta, las investigaciones se han centrado principalmente en propuestas metodológicas útiles para el estudio y valoración del patrimonio presente en el territorio, con criterios que tienen en cuenta tanto el contexto geológico nacional, como su realidad sociopolítica (Palacio-Prieto et al., 2016). Durante las últimas décadas varios autores llamaron la atención de la necesidad de que en Colombia se reconociera al patrimonio geológico por su importancia desde el punto de vista científico, pedagógico, ambiental, turístico, entre otros, resaltando la ausencia de un marco legal especifico dirigido a la protección del patrimonio geológico (Colegial et al., 2002). Hoy, aunque se encuentra en proceso de divulgación e implementación, el patrimonio geológico colombiano ya cuenta con un instrumento legal que propende por su identificación, protección y rehabilitación, el decreto 1353 del 31 de julio de 2018 expedido por el Ministerio de Minas y Energía.

El término Karst se ha usado extensivamente para describir un tipo especial de paisaje formado por procesos de disolución en rocas solubles. En Colombia han sido reportadas cientos de cuevas, encontrándose los sistemas kársticos distribuidos en 21 departamentos (Muñoz-Saba et al., 1998) con la mayoría de las manifestaciones principalmente en la Cordillera
Oriental, donde aisladas áreas kársticas contienen un numero de cuevas significantes (Gunn, 2004). En Santander, existe el registro de 218 geoformas kársticas georreferenciadas en donde cerca del 14\% del área del departamento tiene un potencial alto para el desarrollo de sistemas kársticos, un porcentaje relativamente superior comparado con el de Suramérica donde es menor al 5\% (Galvis-Gómez, 2018).

La existencia de turismo en cuevas (espeleoturismo) depende de muchos factores, como las condiciones específicas de cada cueva, la presencia de infraestructura, atracciones específicas, la relación entre la demanda, el posible flujo de público en la cueva y el conocimiento de los impactos negativos (Figueiredo, 2014). Las cuevas que han sido destinadas para un público más amplio, realizando modificaciones de infraestructura para permitir el acceso son conocidas como show caves, las cuales se utilizan para el espeleoturismo de masa. Actualmente, alrededor de 500 de las show caves más grandes del mundo han beneficiado económicamente a cerca de 100 millones de personas (Cigna y Forti, 2013).

En algunas zonas de Santander donde se llevan a cabo prácticas de espeleoturismo, es común encontrar evidencia de la destrucción de este patrimonio natural irrecuperable, producto de la mala o nula planificación que han tenido estas actividades. En el departamento se ha reportado el uso de cuevas para la disposición de desechos, la destrucción de espeleotemas, grafitis en techos y paredes, material arqueológico saqueado, y en general, graves amenazas a la troglofauna (Gelvez-Chaparro et al., 2018). El territorio de la Provincia de Vélez al sur de Santander presenta un importante desarrollo exo- y endokárstico, siendo la zona del departamento donde más cuevas se han reportado (Figura 1). El objetivo del presente trabajo es contribuir al inventario y valoración del patrimonio natural superficial y subterráneo encontrado en el municipio de El Peñón (Santander), aportando en particular al conocimiento del patrimonio geológico del territorio y planteando estrategias de gestión a partir del desarrollo del geoturismo en un territorio rural que abiertamente se ha opuesto a las prácticas extractivistas. Este inventario de lugares de interés geológico junto a las propuestas de gestión basadas en las valoraciones realizadas, son el primer paso para garantizar la Geoconservación de este patrimonio. 


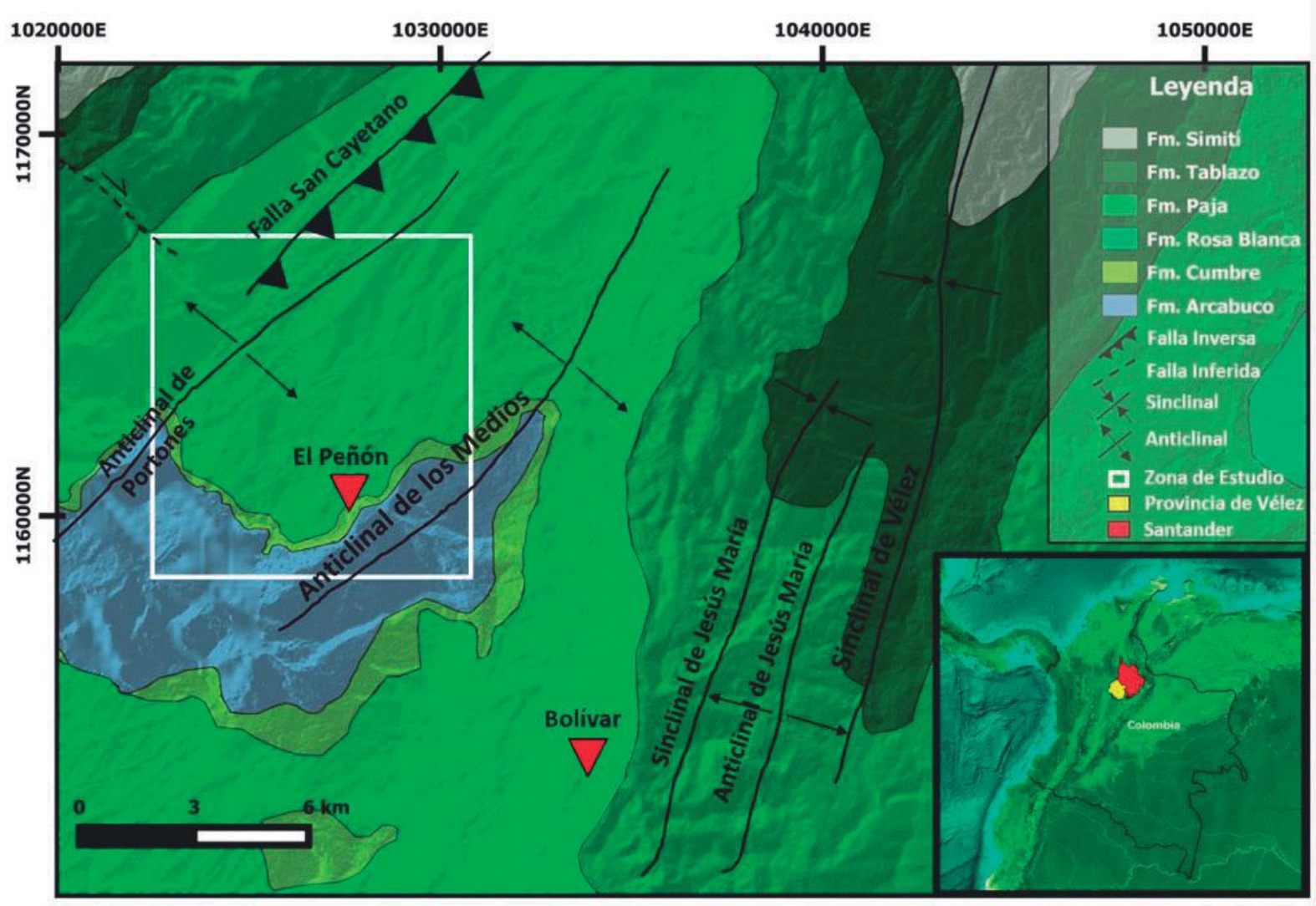

Figura 1. Ubicación del área de estudio en el municipio de El Peñón al sur del departamento de Santander, Colombia. Estructuras geológicas y límites de formaciones tomados de Gómez et al. (2008). Recuadro en la parte inferior derecha tomado y adaptado de Google Satellite.

\section{Marco geológico}

El área de estudio se encuentra localizada geográficamente en el municipio de El Peñón, Provincia de Vélez, al SW del departamento de Santander y a $261 \mathrm{~km}$ de Bucaramanga.

\section{Geología estructural}

Geológicamente está ubicada en las estribaciones occidentales de la Cordillera Oriental (Figura 1) y está limitada por pliegues regionales (Anticlinal de Los Medios, Sinclinal de Panamá y Anticlinal de Los Portones), entre los que se desarrollan plegamientos menores, los cuales siguen un rumbo similar al regional. El desarrollo de las cavernas en El Peñón se da principalmente en direcciones generadas por fracturas de tensión. El tensor local presenta una dirección NWSE $\left(136^{\circ}\right)$ y explica las estructuras plegadas tanto locales como regionales, la perpendicularidad entre las direcciones de preferencia del desarrollo kárstico y el desarrollo de otros patrones de fractura que causan ciertas variaciones en la dirección de estas unidades (Barajas-Rangel y Gelvez-Chaparro, 2019).

\section{Estratigrafía}

A continuación, se describen las unidades presentes en el área de estudio, haciendo énfasis en la Formación Rosablanca, asociada al desarrollo de la karstifición en el área de estudio. La Formación Arcabuco aflora al SW de El Peñón, en el área drenada por la quebrada Hoya de Panamá, en el núcleo del Anticlinal de Los Medios donde solo están expuestos los $32 \mathrm{~m}$ de la parte superior. Es una secuencia de capas de geometría plano-paralela, convergente y cuneiforme, gruesas a muy gruesas, predominando arenitas líticas a lítico feldespáticas de grano fino (Gómez et al., 2008). 
La Formación Cumbre suprayace concordantemente a la Formación Arcabuco y aflora en la terminación periclinal de los anticlinales de Portones y Los Medios, cerca del municipio, donde ocupa una superficie limitada y relativamente cubierta. En el ámbito regional se observa un conjunto de espesor variable, compuesto por capas de arenitas de cuarzo, arcillolitas y lodolitas grises oscuras a negras (Gómez et al., 2008). Según Gómez (1977) en cercanías a El Peñón, algunos diques de cuarzo cortan esta unidad, con desarrollo de drusas y cristales de cuarzo de hasta $12 \mathrm{~cm}$ de longitud.

La Formación Rosablanca aflora en los alrededores de El Peñón, en el núcleo del Anticlinal de Los Medios, en una secuencia de más de $150 \mathrm{~m}$ de espesor, compuesta hacia la base de capas de geometría ondulosa a plano paralela de lodolitas calcáreas (mudstones) de colores grises oscuros, con muy bajo contenido de aloquímicos (bivalvos de escala milimétrica principalmente) y espesores que varían de 0,3 a 0,6 m intercaladas con láminas a capas de arcillolita grises oscuras. En las lodolitas calcáreas de la base es posible encontrar venillas y venas de calcita con trazas de pirita y calcopirita. Algunas venas alcanzan espesores de hasta $15 \mathrm{~cm}$ con cristales muy bien desarrollados de calcita. El siguiente segmento corresponde a una secuencia de cerca de 90 $\mathrm{m}$ de estratos plano paralelos gruesos a muy gruesos de mudstones (de 1 a $5 \mathrm{~m}$ de espesor), de colores grises oscuros intercalados con algunas capas de packstones con mayor contenido fosilífero (principalmente bivalvos y gasterópodos) y arcillolitas grises oscuras. En rocas de esta formación se han encontrado venas de $20 \mathrm{~cm}$ de espesor de cuarzo fibroso mineralizadas, con presencia de calcopirita asociada a barita (Gómez, 1977) y venas de hasta $15 \mathrm{~cm}$ de espesor rellenas de malaquita y azurita mayoritariamente, con galena, barita, calcita, así como otras manifestaciones minerales como calcita, esfalerita, pirita, smithsonita y asfaltita brechificada formadas por procesos kársticos (Mantilla-Figueroa et al., 2003). También se han reportado mineralizaciones secundarias dentro de dolinas al NE del municipio de El Peñón (Gómez, 1977). La Formación Rosablanca, es oblicua respecto a las líneas isocronas; su edad sería Barremiano hacia el extremo N del Valle Medio, Hauteriviano en la región de la Mesa de Los SantosSan Gil y Valanginiano en Villa de Leiva (Julivert, 1968). El drenaje epigeo que se desarrolla sobre la Formación Rosablanca se caracteriza por presentar grandes superficies de infiltración, formando un drenaje subterráneo que controla la disposición y forma de las cavernas (Mendoza-Parada et al., 2009).

\section{Metodología}

Para este trabajo se realizó la cartografía geológica local a escala 1:15.000, en la Cueva del Oro se llevó a cabo el levantamiento topográfico con distanciómetro laser y brújula, para las demás cavernas se realizó la cartografía geoespeleológica con los mapas base de Hapka et al. (2015).

Los sistemas subterráneos objeto de este estudio fueron clasificados de acuerdo a la clasificación espeleométrica propuesta por Núñez (1970), la cual denomina abrigo rocoso a un salón subterráneo de pocos metros, grutas a las cavidades que no superan los $10 \mathrm{~m}$, cuevas cuando son un conjunto de galerías y salones de menos de $1 \mathrm{~km}$ de extensión, y cavernas si su longitud es mayor a $1 \mathrm{~km}$.

La valoración de los geotopos identificados en la zona se desarrolló con la metodología Modified Geosite Assessment Model (M-GAM) propuesta por Tomić y Božić (2014), que a su vez es una modificación de la metodología Geosite Assessment Model (GAM) creada por Vujičić et al. (2011). Esta metodología pretende ser más objetiva a la hora de evaluar un sitio, teniendo en cuenta las diferentes motivaciones que podría tener un turista para visitar un geositio (elementos socio-culturales, históricos, escénicos, arqueológicos, educativos, científicos, de diversión, psicológicos y artísticos), reconoce el importante rol que juega el turista a la hora de evaluar un geositio, por lo que en la metodología de evaluación incluye la opinión del experto como la del turista, de tal manera que ninguna de las partes sea favorecida en el proceso de evaluación. Este método ha sido probado y aplicado con éxito numerosas veces para la evaluación de varios geositios en Europa (Antić y Tomić, 2017; Antić et al., 2019; Božić y Tomić, 2015; Šuleić y Pavić, 2016; Tomić et al., 2015; Vuković y Antić, 2019).

Los Valores Principales comprenden tres grupos de indicadores: Científico/Educativo (VCE), Escénico/ Estético (VEE) y de Protección (VPr) mientras los Valores Adicionales están divididos en dos grupos de indicadores, Funcional (VFn) y Turístico (VTr). En resumen, hay 12 subindicadores de Valores Principales, y 15 subindicadores de Valores Adicionales los cuales son calificados de 0 a 1 (Tablas 1 y 2) que define M-GAM como una simple ecuación:

$$
\mathrm{M}-\mathrm{GAM}=\mathrm{VP}+\mathrm{VA}
$$


Como de cada uno de los anteriores valores nombrados se derivan tres o dos grupos de subindicadores, entonces podemos inferir estas dos ecuaciones:

$$
\begin{gathered}
\mathrm{VP}=\mathrm{VCE}+\mathrm{VEE}+\mathrm{VPr} \quad \text { (2) pueden ser escritas como sigue } \\
\mathrm{VP}=\mathrm{VCE}+\mathrm{VEE}+\mathrm{VPr}=\sum_{i=1}^{12} S I V P i ; \text { donde, } 0 \leq \operatorname{SIV} P \leq 1 . \\
\mathrm{VA}=\mathrm{VFn}+\mathrm{VTr}=\sum_{j=1}^{15} S I V A j ; \text { donde, } 0 \leq S I V A \leq 1 .
\end{gathered}
$$

$$
\mathrm{VA}=\mathrm{VFn}+\mathrm{VTr}
$$

Ahora que sabemos que cada grupo de indicadores consiste en varios subindicadores, entonces (2) y (3) pueden ser escritas como sigue a continuación:
Aquí, $S I V P_{i}$ y $S I V A_{j}$ representan los 12 subindicadores de Valores Principales $(i=1, \ldots, 12)$ y 15 subindicadores $(\mathrm{j}=1, \ldots, 15)$ de Valores Adicionales.

La inclusión del visitante en el proceso de valoración es hecha a través de una encuesta donde a cada persona se le pide que califique la importancia de todos los 27 subindicadores (de 0,00 a 1,00) en el modelo M-GAM, para este trabajo se recogió la opinión de cerca de 20 turistas, quienes además fueron motivados a través de visitas guiadas y explicativas como parte del proceso de geoeducación a partir de los valores científicos y educativos de los geotopos de interés en el presente estudio. El factor de importancia ( $\mathrm{Im}$ ) les da a los visitantes la oportunidad de expresar su opinión acerca de cada subindicador en el modelo y que tan importante es para ellos cuando escogen y deciden entre varios geositios que ellos desean visitar. Luego de que cada visitante califique la importancia de cada subindicador, el valor promedio de cada subindicador es calculado y el valor final de ese subindicador es el factor de importancia. Después, el valor de importancia (Im) es multiplicado con el valor dado por expertos (también de 0,00 a 1,00 ) que evalúan el estado actual y valor de los subindicadores.

Así, el factor de importancia (Im) es definido, como:

$$
\operatorname{Im}=\frac{\sum_{k=1}^{K} I v_{k}}{K}
$$

Donde $I v_{k}$ es la evaluación/puntuación de un visitante por cada subindicador y $\mathrm{K}$ es el total de número de visitantes.

Finalmente, la ecuación (1) puede ser expresada de la siguiente forma:

$$
\mathrm{M}-\mathrm{GAM}=\mathrm{VP}+\mathrm{VA}=\sum_{i=1}^{12} I m_{i} \cdot V P_{i}+\sum_{j=1}^{15} I m_{j} \cdot V A_{j}
$$

Como se puede ver a partir de la ecuación M-GAM, el valor del factor de importancia (Im), el cual es calificado por visitantes (para cada subindicador separadamente) es multiplicado con el valor dado por expertos (también separadamente cada subindicador). Esto es hecho para cada subindicador en el modelo.

En base a los resultados de la evaluación, se crea una matriz de VP (ejes X) y VA (ejes Y). La matriz se divide en nueve campos representados con $Z(i, j),(i, j$ $=1,2,3, \ldots)$. Dependiendo de la puntuación final, cada geositio se ajustará a un campo determinado.

Además de la valoración, un índice estandarizado: el Índice de Sensibilidad de Cuevas (CSI) (Tabla 3) fue aplicado a las cavernas para determinar su sensibilidad de acuerdo a la metodología propuesta por Harley et al. (2011). Las cuevas pueden ser sensibles a muchos factores en el ambiente, pero en este estudio se buscará solo determinar la sensibilidad de las cuevas a las perturbaciones antropogénicas. Para estandarizar este índice, se consideraron las variables de biota, hidrología, geología, mineralogía, paleontología y cultura o historia. Cada variable fue estandarizada dentro de cuatro criterios de evaluación, los cuales se correlacionan a un puntaje de sensibilidad. La escala de sensibilidad va desde "0", sin sensibilidad, a "3" indicando una alta sensibilidad.

Los puntajes de cada variable de sensibilidad fueron sumados y después este resultado se dividió por el puntaje total posible, que resulta en un número final 
entre 0,00 y 1,00 . Este número final representa la sensibilidad relativa de una cueva a la degradación humana, representando el puntaje más cercano a uno una mayor sensibilidad general de la cueva (Tabla 4).

Tabla 1. Estructura del Modelo de Evaluación de Geositios Modificado.

\begin{tabular}{|c|c|c|}
\hline \multicolumn{2}{|r|}{ Indicadores/ Subindicadores } & \multirow[b]{2}{*}{ Valores Principales (VP) } \\
\hline & & \\
\hline \multicolumn{3}{|r|}{ Valor Científico/Educacional (VCE) } \\
\hline & Rareza & Número de sitios idénticos más cercanos \\
\hline 2. & Representatividad & $\begin{array}{l}\text { Características didácticas y ejemplares del sitio debido a su propia calidad y } \\
\text { configuración general }\end{array}$ \\
\hline 3. & $\begin{array}{l}\text { Conocimiento sobre temas } \\
\text { geocientíficos }\end{array}$ & $\begin{array}{l}\text { Número de artículos escritos en revistas reconocidas, tesis, presentaciones y otras } \\
\text { publicaciones }\end{array}$ \\
\hline 4. & Nivel de interpretación & $\begin{array}{l}\text { Nivel de posibilidades interpretativas sobre procesos, fenómenos geológicos y } \\
\text { geomorfologicos }\end{array}$ \\
\hline \multicolumn{3}{|r|}{ Valor Escénico/Estético (VEE) } \\
\hline 5. & Puntos de Vista & $\begin{array}{l}\text { Número de puntos de vista accesibles por un camino peatonal. Cada uno debe } \\
\text { presentar un ángulo de visión particular y estar situado a menos de } 1 \mathrm{~km} \text { del sitio }\end{array}$ \\
\hline 6. & Superficie & $\begin{array}{l}\text { Toda la superficie del sitio. Cada sitio se considera en relación cuantitativa con otros } \\
\text { sitios }\end{array}$ \\
\hline 7. & Paisaje circundante y Naturaleza. & $\begin{array}{l}\text { Calidad de la vista panorámica, presencia de agua y vegetación, ausencia de deterioro } \\
\text { inducido por el hombre, área urbana vecina, etc. }\end{array}$ \\
\hline 8. & $\begin{array}{l}\text { Adaptación ambiental de los } \\
\text { sitios. }\end{array}$ & Nivel de contraste con la naturaleza, contraste de colores, apariencia de formas, etc. \\
\hline \multicolumn{3}{|r|}{ Valor de Protección (VPr) } \\
\hline & Condición Actual & Estado actual de geositio \\
\hline & Nivel de Protección & $\begin{array}{l}\text { Protección por grupos locales o regionales, gobierno nacional, organizaciones } \\
\text { internacionales, etc. }\end{array}$ \\
\hline & Vulnerabilidad & Nivel de vulnerabilidad del geositio \\
\hline & Cantidad adecuada de visitantes & Número propuesto de visitantes en el sitio al mismo tiempo \\
\hline \multicolumn{3}{|r|}{ Valores Adicionales (VA) } \\
\hline \multicolumn{3}{|r|}{ Valores Funcionales (VFn) } \\
\hline & Accesibilidad & Posibilidades de aproximación al sitio \\
\hline & Valores naturales adicionales & $\begin{array}{l}\text { Número de valores naturales adicionales en un radio de } 5 \mathrm{~km} \text { (incluidos también } \\
\text { geositios) }\end{array}$ \\
\hline & $\begin{array}{l}\text { Valores antropogénicos } \\
\text { adicionales }\end{array}$ & Número de valores antropogénicos adicionales en un radio de $5 \mathrm{~km}$ \\
\hline & Centros emisivos vecinos & Cercanía de centros emisivos \\
\hline & $\begin{array}{l}\text { Importante red de carreteras } \\
\text { vecinas }\end{array}$ & Cercanía de importantes redes de carreteras en un radio de $20 \mathrm{~km}$ \\
\hline & Valores funcionales adicionales & Estacionamientos, estaciones de servicio, mecánicos, etc. \\
\hline \multicolumn{3}{|r|}{ Valores Turísticos (VTr) } \\
\hline & Promoción & Nivel y número de fuentes promocionales \\
\hline & Visitas Organizadas & Número anual de visitas organizadas al geositio \\
\hline & Centros de visitantes vecinos & Cercanía del centro de visitantes al geositio \\
\hline & Paneles interpretativos & $\begin{array}{l}\text { Características interpretativas de texto y gráficas, calidad del material, tamaño, ajuste } \\
\text { al entorno, etc. }\end{array}$ \\
\hline & Número de visitantes & Número anual de visitantes \\
\hline 24. & Infraestructura turística & $\begin{array}{l}\text { Nivel de infraestructura adicional para turistas (senderos peatonales, lugares de } \\
\text { descanso, botes de basura, baños, etc.) }\end{array}$ \\
\hline & Servicio de guía turístico & $\begin{array}{l}\text { Si existe, nivel de experiencia, conocimiento de idiomas extranjeros, habilidades } \\
\text { interpretativas, etc. }\end{array}$ \\
\hline & Servicio de hostelería & Servicio de hostelería cerca del geositio \\
\hline & Servicio de restaurante & Servicio de restaurante cerca del geositio \\
\hline
\end{tabular}


Tabla 2. Valores asociados a los indicadores del Modelo de Evaluación de Geositios Modificado.

\begin{tabular}{|c|c|c|c|c|c|}
\hline \multirow[t]{2}{*}{ Indicadores } & \multicolumn{5}{|c|}{ Grados $(0,00-1,00)$} \\
\hline & 0,00 & 0,25 & 0,50 & 0,75 & 1,00 \\
\hline 1. & Común & Regional & Nacional & Internacional & La única ocurrencia \\
\hline 2. & Ninguna & Baja & Moderada & Alta & Mayor \\
\hline 3. & Ninguna & $\begin{array}{l}\text { Publicaciones } \\
\text { locales }\end{array}$ & $\begin{array}{l}\text { Publicaciones } \\
\text { regionales }\end{array}$ & $\begin{array}{l}\text { Publicaciones } \\
\text { nacionales }\end{array}$ & $\begin{array}{l}\text { Publicaciones } \\
\text { internacionales }\end{array}$ \\
\hline 4. & Ninguna & $\begin{array}{l}\text { Moderado nivel de } \\
\text { procesos pero difícil } \\
\text { de explicar a no } \\
\text { expertos }\end{array}$ & $\begin{array}{l}\text { Buen ejemplo de } \\
\text { procesos pero difícil } \\
\text { de explicar para no } \\
\text { expertos }\end{array}$ & $\begin{array}{l}\text { Moderado nivel de } \\
\text { procesos, pero fácil } \\
\text { de explicar para } \\
\text { visitantes comunes }\end{array}$ & $\begin{array}{l}\text { Buen ejemplo de } \\
\text { procesos y fácil de } \\
\text { explicar a visitantes } \\
\text { comunes }\end{array}$ \\
\hline 5. & Ninguna & 1 & 2 a 3 & 4 a 6 & Más de 6 \\
\hline 6. & Pequeña & - & Medio & - & Grande \\
\hline 7. & - & Bajo & Medio & Alto & Mayor \\
\hline 8. & Impropio & - & Neutral & - & Adecuado \\
\hline 9. & $\begin{array}{l}\text { Totalmente } \\
\text { dañado (por } \\
\text { actividades } \\
\text { humanas) }\end{array}$ & $\begin{array}{l}\text { Altamente dañado } \\
\text { (resultado de } \\
\text { procesos naturales) }\end{array}$ & $\begin{array}{l}\text { Medio dañado } \\
\text { (con esenciales } \\
\text { características } \\
\text { geomorfológicas } \\
\text { preservadas) }\end{array}$ & Ligeramente dañado & Sin daño \\
\hline 10. & Ninguno & Local & Regional & Nacional & Internacional \\
\hline 11. & $\begin{array}{l}\text { Irreversible (con } \\
\text { posibilidad de } \\
\text { pérdida total) }\end{array}$ & $\begin{array}{l}\text { Alta (podría ser } \\
\text { fácilmente dañado) }\end{array}$ & $\begin{array}{l}\text { Medio (podría ser } \\
\text { dañado por procesos } \\
\text { naturales o actividades } \\
\text { humanas) }\end{array}$ & $\begin{array}{l}\text { Bajo (podría } \\
\text { ser dañado solo } \\
\text { por actividades } \\
\text { humanas) }\end{array}$ & Ninguna \\
\hline 12. & 0 & 0 a 10 & 10 a 20 & 20 a 50 & Más de 50 \\
\hline 13. & Inaccesible & $\begin{array}{l}\text { Bajo (a pie con } \\
\text { equipamiento } \\
\text { especial y guía } \\
\text { turístico experto) }\end{array}$ & $\begin{array}{l}\text { Medio (por bicicleta } \\
\text { y otras formas de } \\
\text { transporte impulsadas } \\
\text { por el hombre) }\end{array}$ & Alto (por carro) & Mayor (por bus) \\
\hline 14. & Ninguno & 1 & 2 a 3 & 4 a 6 & Más de 6 \\
\hline 15. & Ninguno & 1 & 2 a 3 & 4 a 6 & Más de 6 \\
\hline 16. & Más de 100 km & 100 a $50 \mathrm{~km}$ & 50 a $25 \mathrm{~km}$ & 25 a $5 \mathrm{~km}$ & Menos de $5 \mathrm{~km}$ \\
\hline 17. & Ninguna & Local & Regional & Nacional & Internacional \\
\hline 18. & Ninguno & Bajo & Medio & Alto & Mayor \\
\hline 19. & Ninguna & Local & Regional & Nacional & Internacional \\
\hline 20. & Ninguna & Menos de 12 por año & 12 a 24 por año & 24 a 48 por año & Más de 48 por año \\
\hline 21. & Más de 50 km & 50 a $20 \mathrm{~km}$ & 20 a $5 \mathrm{~km}$ & 5 a $1 \mathrm{~km}$ & Menos de $1 \mathrm{~km}$ \\
\hline 22. & Ninguno & Baja calidad & Calidad media & Alta calidad & Mayor calidad \\
\hline 23. & Ninguna & $\begin{array}{l}\text { Baja (menos de } \\
5000)\end{array}$ & Medio (5001 a 1000) & $\begin{array}{l}\text { Alta }(10001 \mathrm{a} \\
100000)\end{array}$ & $\begin{array}{l}\text { Mayor (más de } \\
100000 \text { ) }\end{array}$ \\
\hline 24. & Ninguna & Baja & Media & Alta & Mayor \\
\hline 25. & Ninguna & Baja & Media & Alta & Mayor \\
\hline 26. & Más de 50 km & $25-50 \mathrm{~km}$ & $10-25 \mathrm{~km}$ & $5-10 \mathrm{~km}$ & Menos que $5 \mathrm{~km}$ \\
\hline 27. & Más de $25 \mathrm{~km}$ & $10-25 \mathrm{~km}$ & $10-5 \mathrm{~km}$ & $1-5 \mathrm{~km}$ & Menos de $1 \mathrm{~km}$ \\
\hline
\end{tabular}


Tabla 3. Variables para el cálculo del Índice de Sensibilidad de Cuevas (CSI). Adaptado de Harley et al. (2011).

\begin{tabular}{|c|c|c|c|c|}
\hline Variable & 3 & 2 & 1 & $\mathbf{0}$ \\
\hline Biota & $\begin{array}{l}\text { Gran cantidad de individuos de una } \\
\text { especie o múltiples individuos de múltiples } \\
\text { especies; presencia de especies en peligro o } \\
\text { endémicas; o posibles nuevas especies }\end{array}$ & $\begin{array}{l}\text { Varios individuos de } \\
\text { una o varias especies }\end{array}$ & $\begin{array}{c}\text { Pocas especies de una o } \\
\text { varias especies }\end{array}$ & Sin recursos \\
\hline Hidrología & $\begin{array}{c}\text { Conexión directa con el acuífero; flujo } \\
\text { interno de agua continuo o intermitente; } \\
\text { goteo, filtraciones y presencia de piscinas } \\
\text { y charcas }\end{array}$ & $\begin{array}{l}\text { Goteos, filtraciones y } \\
\text { charchas en múltiples } \\
\text { áreas }\end{array}$ & $\begin{array}{l}\text { Escasez o filtraciones, } \\
\text { charcas y goteos } \\
\text { localizados }\end{array}$ & Sin recursos \\
\hline Geología & Abundancia de espeleotemas & $\begin{array}{l}\text { Espeleotemas en } \\
\text { múltiples áreas }\end{array}$ & $\begin{array}{c}\text { Escasez o espeleotemas } \\
\text { localizados }\end{array}$ & Sin recursos \\
\hline Mineralogía & $\begin{array}{l}\text { Abundancia de minerales o presencia de } \\
\text { nuevos minerales }\end{array}$ & $\begin{array}{l}\text { Revestimientos } \\
\text { minerales en múltiples } \\
\text { áreas }\end{array}$ & $\begin{array}{l}\text { Escasez de ocurrencias } \\
\text { minerales (revestimientos } \\
\text { minerales) }\end{array}$ & Sin recursos \\
\hline Paleontología & Abundancia de fósiles (en roca) & $\begin{array}{c}\text { Fósiles en múltiples } \\
\text { áreas }\end{array}$ & $\begin{array}{l}\text { Escasez de ocurrencia de } \\
\text { fósiles }\end{array}$ & Sin recursos \\
\hline $\begin{array}{l}\text { Cultura o } \\
\text { Historia }\end{array}$ & Caverna en zona protegida & $\begin{array}{l}\text { Elementos culturales en } \\
\text { múltiples áreas }\end{array}$ & $\begin{array}{l}\text { Escasez u ocurrencias } \\
\text { localizadas de elementos } \\
\text { culturales }\end{array}$ & Sin recursos \\
\hline
\end{tabular}

Tabla 4. Clasificaciones de sensibilidad de cuevas. Adaptado de Harley et al. (2011).

\begin{tabular}{cc}
\hline Puntaje (suma/suma total posible) & Grado de sensibilidad \\
\hline $0,81-1,00$ & Críticamente sensible \\
$0,71-0,80$ & Severamente sensible \\
$0,61-0,70$ & Considerablemente sensible \\
$0,51-0,60$ & Sensible \\
$0,40-0,50$ & Moderadamente sensible \\
$0,20-0,39$ & Ligeramente sensible \\
$0,00-0,19$ & Sin sensibilidad \\
\hline
\end{tabular}

\section{Resultados}

La Formación Rosablanca es la unidad litoestratigráfica que predomina en la zona (Figura 2), presenta precipitaciones de sulfuros como pirita, galena y esfalerita; estas manifestaciones minerales también se pueden encontrar en venillas de reemplazamiento $\mathrm{y}$ venas de relleno, estas últimas asociadas a actividad hidrotermal, compuestas de calcita principalmente con cristales de pirita y calcopirita en menor proporción.

De los seis lugares de interés geológico valorados, cinco son formados por procesos kársticos asociados a la Formación Rosablanca; su expresión superficial o geoformas exokársticas son principalmente los lapiaces (karren), los cuales ocurren generalmente en distintos tamaños, desde pocos milímetros (microkarren) hasta lapiaces de $6 \mathrm{~m}$ de altura (megakarren), donde predominan los procesos disolucionales por flujo de agua (rillenkarren, rinnenkarren, meanderkarren, wandkarren, trittkarren, karren caves, scallops, ripplekarren), desarrollados en los márgenes de las dolinas.

Las dolinas son las depresiones predominantes en la zona, poseen formas elípticas y circulares con diámetros de 5 a $35 \mathrm{~m}$, algunas de estas han evolucionado más en el eje vertical produciendo en algunos casos la aparición de simas de pocos diámetros en su mayoría, aunque existen simas de grandes diámetros como la de la Caverna La Tronera. En la zona las dolinas se han desarrollado en direcciones preferenciales $\mathrm{N} 65^{\circ} \mathrm{W}$ y $\mathrm{N} 50^{\circ} \mathrm{E}$, con una dirección secundaria $\mathrm{N} 15^{\circ} \mathrm{W}$. Estas alineaciones favorecen la unión entre dolinas que con el tiempo muy seguramente evolucionarán a úvalas y seguidamente a poljes o valles de dolinas. La existencia de manantiales kársticos, además de los numerosos abrigos rocosos, grutas, cuevas y cavernas en la zona, denotan la amplia variedad y cantidad de geoformas kársticas presentes (Figura 3). 


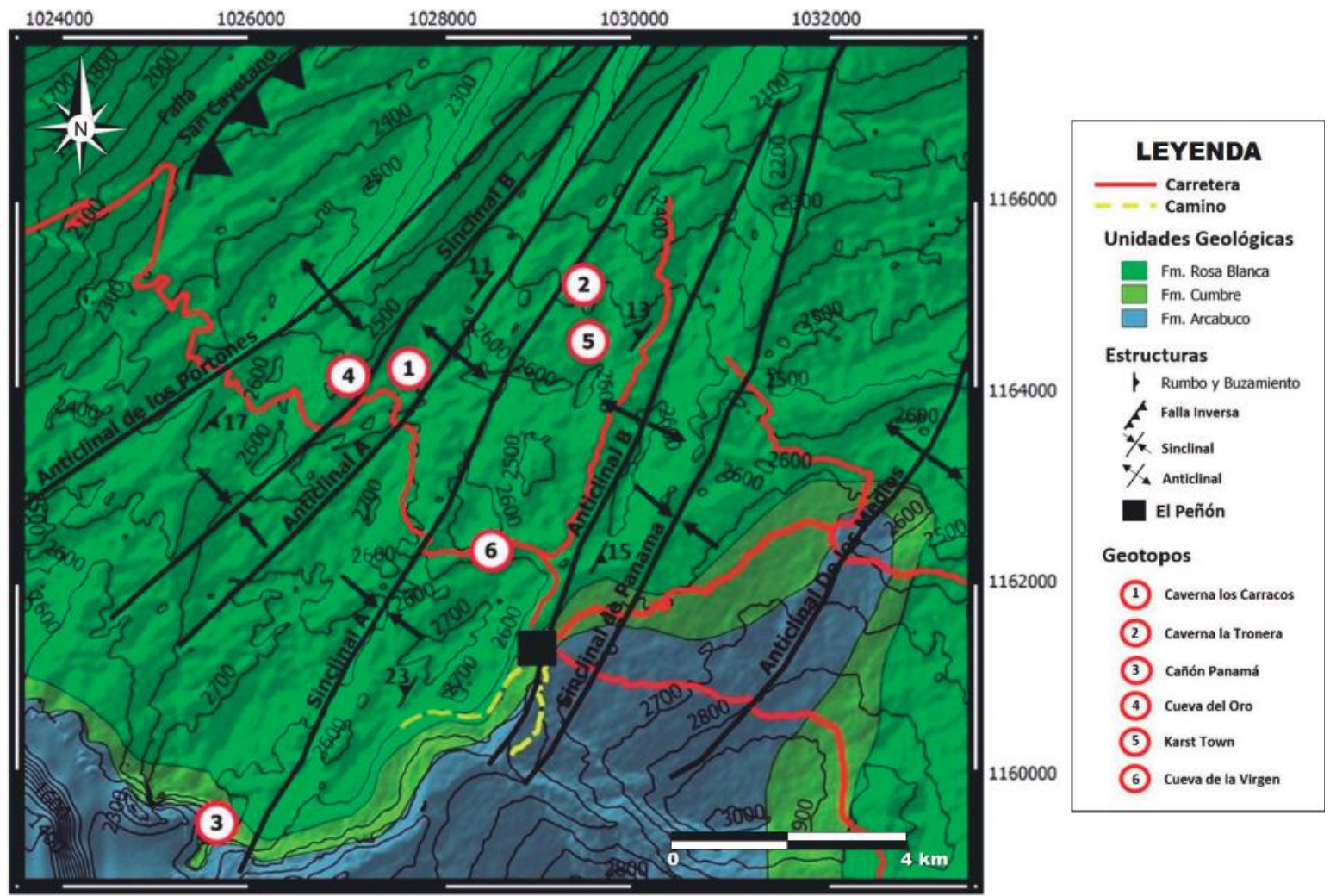

Figura 2. Mapa geológico del área de estudio y ubicación de los geotopos valorados en el presente trabajo.
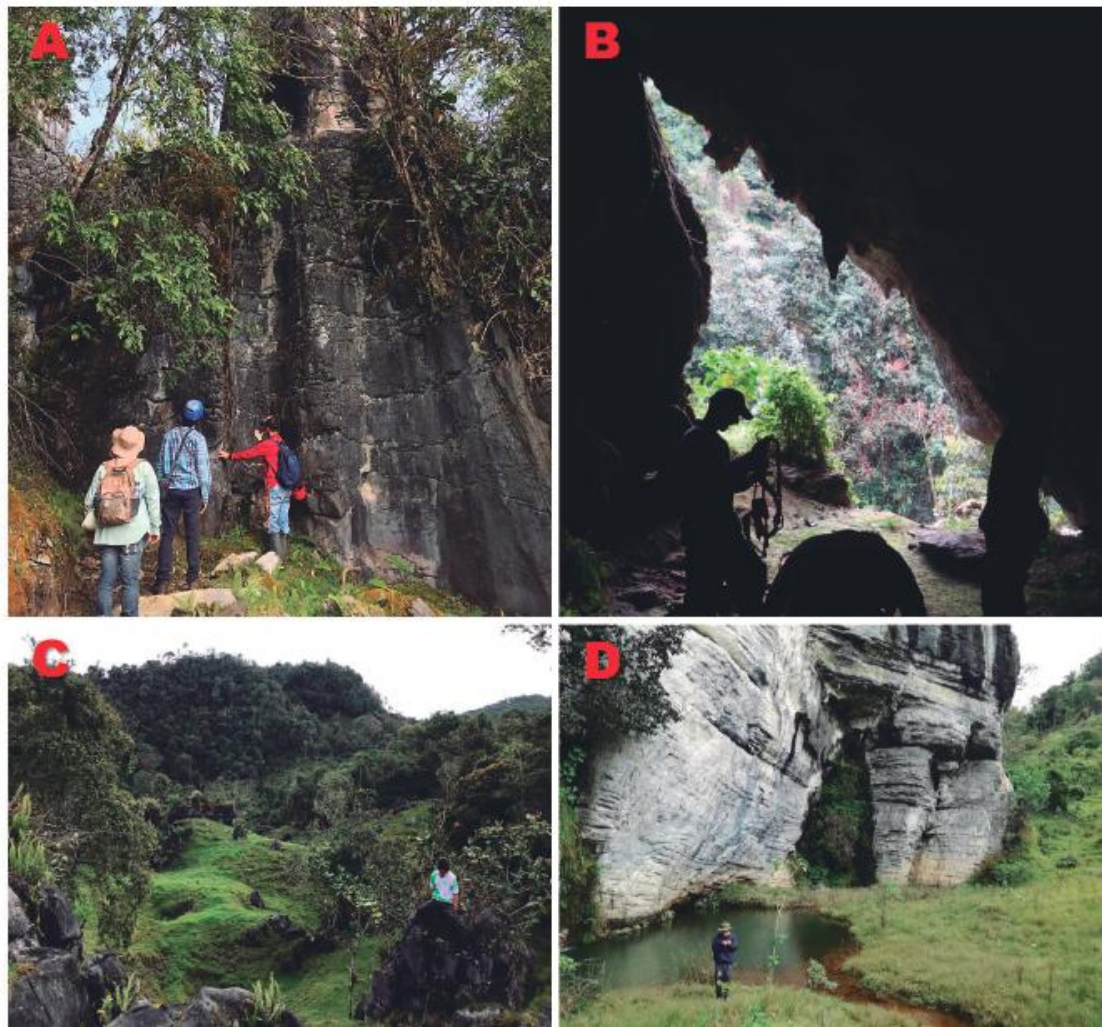

Figura 3. Geoformas exokársticas y endokársticas: A. Megakarren de cerca de $7 \mathrm{~m}$. B. Entrada a la Caverna Los Carracos. C. Campo de lapiaces y dolinas. D. Manantial Kárstico. 


\section{Geotopos}

A continuación, se describen los primeros lugares de interés geológico (o geotopos) identificados en cercanías al municipio de El Peñón y los cuales son el objeto de interés de este trabajo. En los geotopos subterráneos se propone la distinción entre rutas científicas y rutas geoturisticas, en las primeras se hace alusión a espacios donde no se permita el acceso al público en general, sino a un tipo de público especializado con interés en desarrollar estudios que contribuyan al conocimiento y Geoconservación del sistema kárstico. Esta distinción en las rutas se hace por la sensibilidad a la degradación humana que presentan estos espacios, debido a sus condiciones espeleométricas y a la diversidad de elementos geológicos y paleontológicos que se encuentran en estas secciones.

\section{Caverna Los Carracos}

La Caverna Los Carracos se encuentra en la vereda Llano de Vargas, al costado de un polje con una altura aproximada de $2600 \mathrm{msnm}$. Con la profundización del desarrollo kárstico en el tiempo, se han desarrollado tres niveles que se disponen en cuatro direcciones preferenciales dos de ellas ortogonales a $236^{\circ}$ y $319^{\circ}$ en azimut, las otras dos direcciones son oblicuas a estas, $183^{\circ}$ y $207^{\circ}$ en azimut, con un mayor y menor desarrollo respectivamente. En el nivel superior existe desarrollo y ciertas variedades de espeleotemas, pero la preservación de los salones y galerías ha sido afectada parcialmente por las constantes visitas tanto de locales como de turistas sin una conciencia de conservación, por eso en este sector se ha definido el recorrido turístico (Figura 4), además de que sus dimensiones espeleométricas son más favorables para el acceso y recorrido.

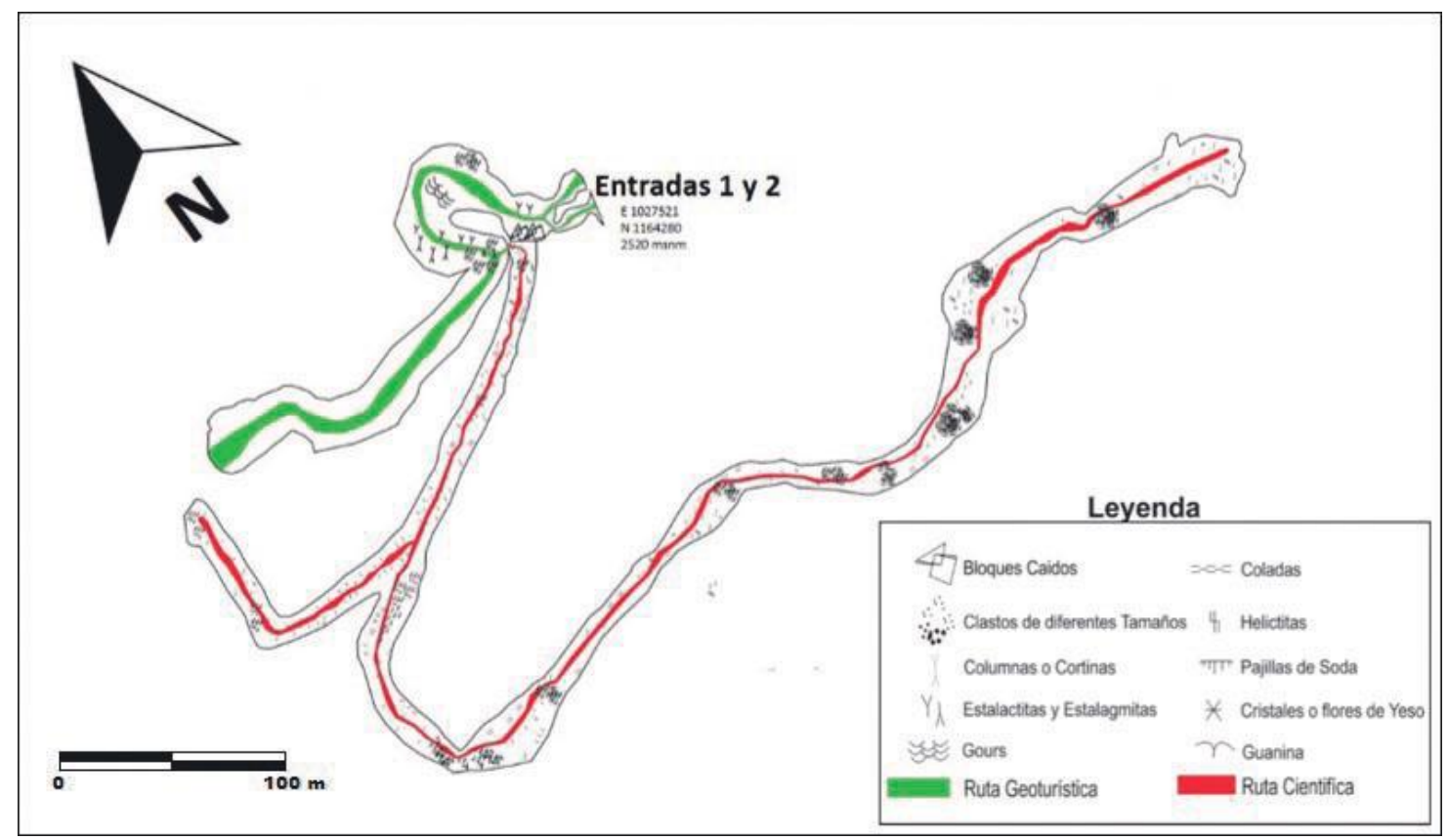

Figura 4. Mapa de la Caverna Los Carracos (modificado de Hapka et al., 2015).

Para acceder al siguiente nivel es necesario hacer un descenso en la vertical de unos $20 \mathrm{~m}$ aproximadamente (Figura 5), razón principal por la cual es en esta galería en donde se preservan la mayor variedad de espeleotemas en cuanto a forma y composición (antoditas, helictitas, flores de yeso, gours, entre otras). En este nivel inferior se han desarrollado importantes investigaciones principalmente en los campos de la bioespeleología (Campos et al., 2018) y la paleoclimatología (Ramirez-Ruiz, 2014); el potencial de la galería inferior prioriza la actividad científica en esta sección y es necesario mantenerlo así para aprovechar los datos y/o registros que pueden brindar los espeleotemas que han sido preservados de manera excepcional. 

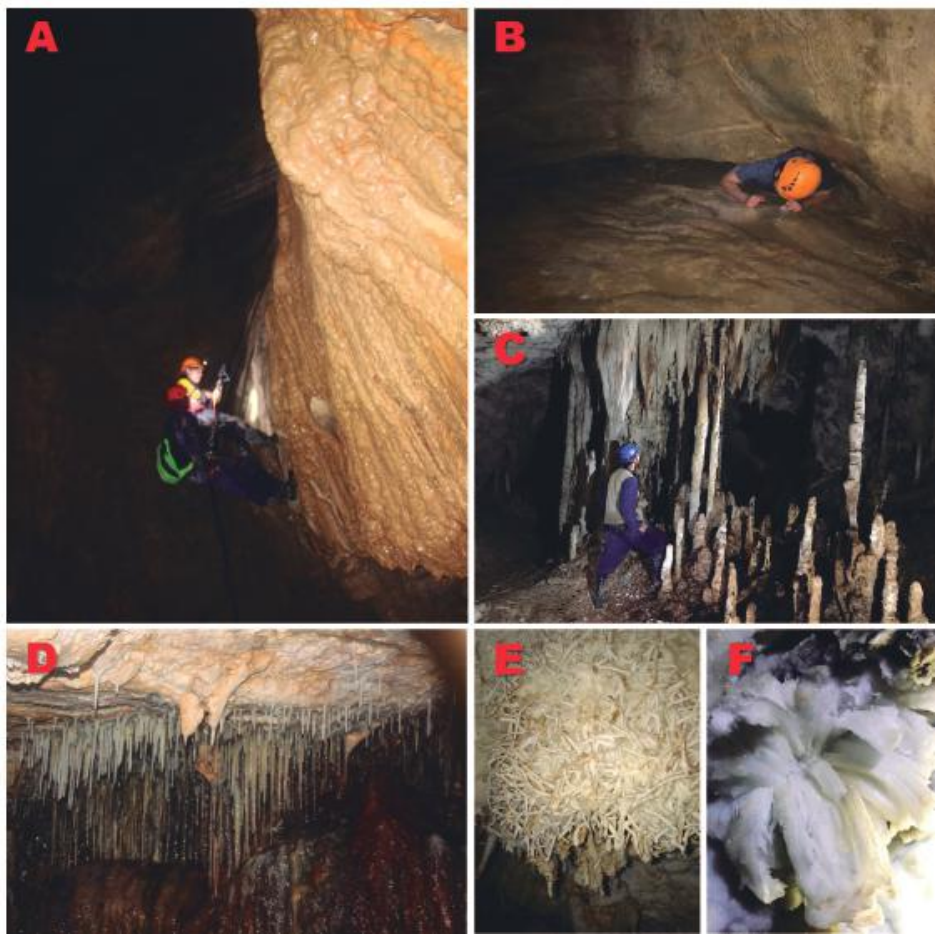

Figura 5. Galería inferior de la Caverna Los Carracos. A. Descenso para acceder a la galería inferior. B. Acceso al descenso para acceder a la galería inferior. C. Espeleotemas de la galería inferior de la Caverna Los Carracos. D. Espeleotemas Cenitales y Parietales con precipitación de Mn. E. Excéntricas. F. Flor de yeso.

\section{Caverna La Tronera}

La Caverna La Tronera se encuentra en la vereda San Pablo al NE del municipio de El Peñón, a 2650 $\mathrm{msnm}$. Presenta un desarrollo de cerca de $1,3 \mathrm{~km}$ con dos entradas, una vertical y una horizontal bastante amplia por donde hay que atravesar un camino de bloques bastante grandes y angulosos producto del colapso del techo de la caverna, con sedimentos de inundación depositados sobre estos; la entrada horizontal a la caverna se formó en el pasado debido a la caída del nivel piezométrico, dejando la cavidad de estar inundada. La caverna está formada por una gigante galería principal sin actividad hídrica con una dirección promedio de $325^{\circ}$ de azimut (Figura 6), y con un desarrollo menor en $210^{\circ}$ y $240^{\circ}$, hacia donde se presenta el frente de karstificación.

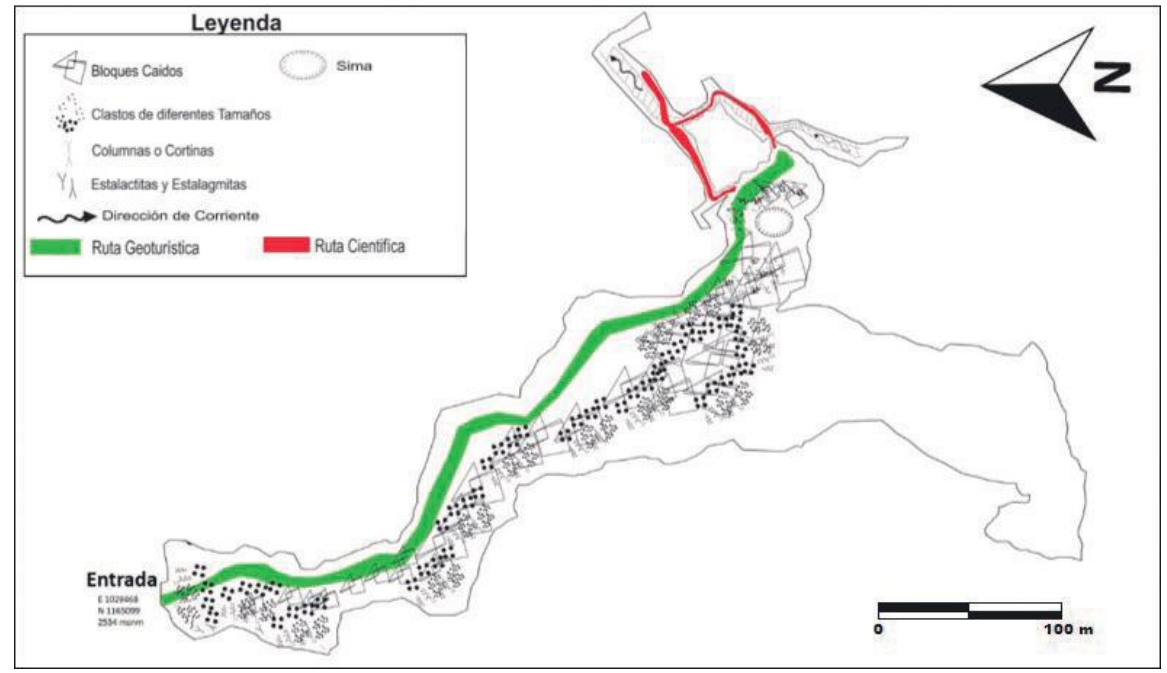

Figura 6. Mapa de la Caverna La Tronera (modificado de Hapka et al., 2015). 
En el techo de la entrada horizontal, a más de 100 $\mathrm{m}$ tienen su hogar un buen número de Guácharos o Carracos (Steatornis caripensis) que con sus cantos dan un ambiente enigmático a la incursión subterránea. La entrada vertical es una dolina de colapso o sima ubicada a unos $700 \mathrm{~m}$ de la entrada y constituye su principal atractivo turístico, está a una altura de cerca de $130 \mathrm{~m}$ y un diámetro de aproximadamente $25 \mathrm{~m}$, simulando su forma en planta a la de un corazón, por lo que se ha denominado esta geoforma por la comunidad local como "el corazón del mundo" (Figura 7), en esta sección de la caverna se planteó el recorrido turístico debido a que las dimensiones espeleométricas son bastante amplias permitiendo una movilidad sencilla a través de esta y llegando a causar un impacto mínimo sobre el ecosistema.
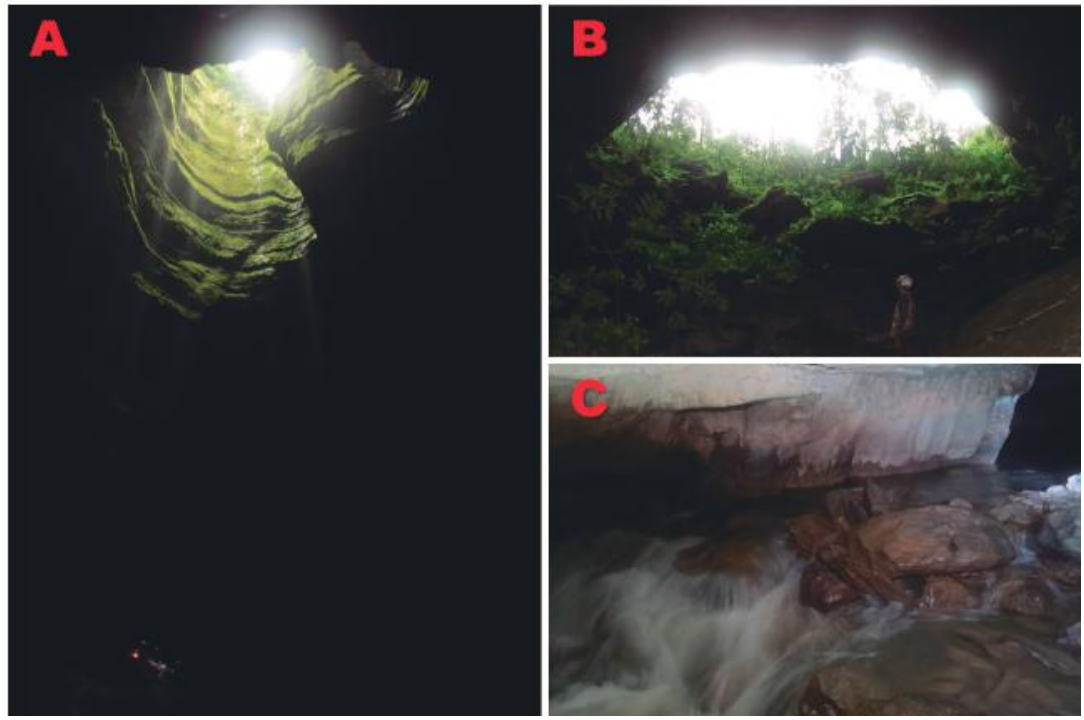

Figura 7. Caverna La Tronera: A. Sima de cerca de 150 m, "el corazón del mundo". B. Entrada horizontal de la Caverna La Tronera, con gran cantidad de bloques angulares de gran tamaño. C. Quebrada subterránea.

\section{Cueva del Oro}

Su nombre se debe a la gran cantidad de azufre que hay principalmente en la entrada de la caverna, dando un valor agregado a la belleza de los espeleotemas. La cavidad se desarrolla al final de un valle de dolinas, y se encuentra constituida por un nivel predominantemente horizontal con diferentes ramificaciones, registrándose en este trabajo un desarrollo de $630 \mathrm{~m}$ para esta cueva, pero su extensión es mucho mayor, por lo que se recomiendan nuevas incursiones que mapeen las galerías faltantes. La cueva se desarrolla en dos direcciones preferenciales con un patrón ortogonal, con direcciones de $320^{\circ}$ y $235^{\circ}$ de azimut (Figura
Cerca de la zona de la sima hay una entrada pequeña donde se llega a una quebrada o rio subterráneo con dirección SW-NE, en invierno es imposible ingresar por el alto caudal de esta; pero algunas exploraciones de la Sociedad Colombiana de Espeleología han encontrado un importante desarrollo en este sector donde también se han reportado algunas simas y acumulación de restos fósiles de mamíferos, debido a los peligros y a la riqueza paleontológica presente en el caudal se ha planteado un recorrido netamente científico en esta sección de la caverna. Las simas se han demostrado son una trampa para los animales del exterior favoreciendo la posible abundancia de fósiles en el fondo de estas (Llopis-Lladó, 1970). 


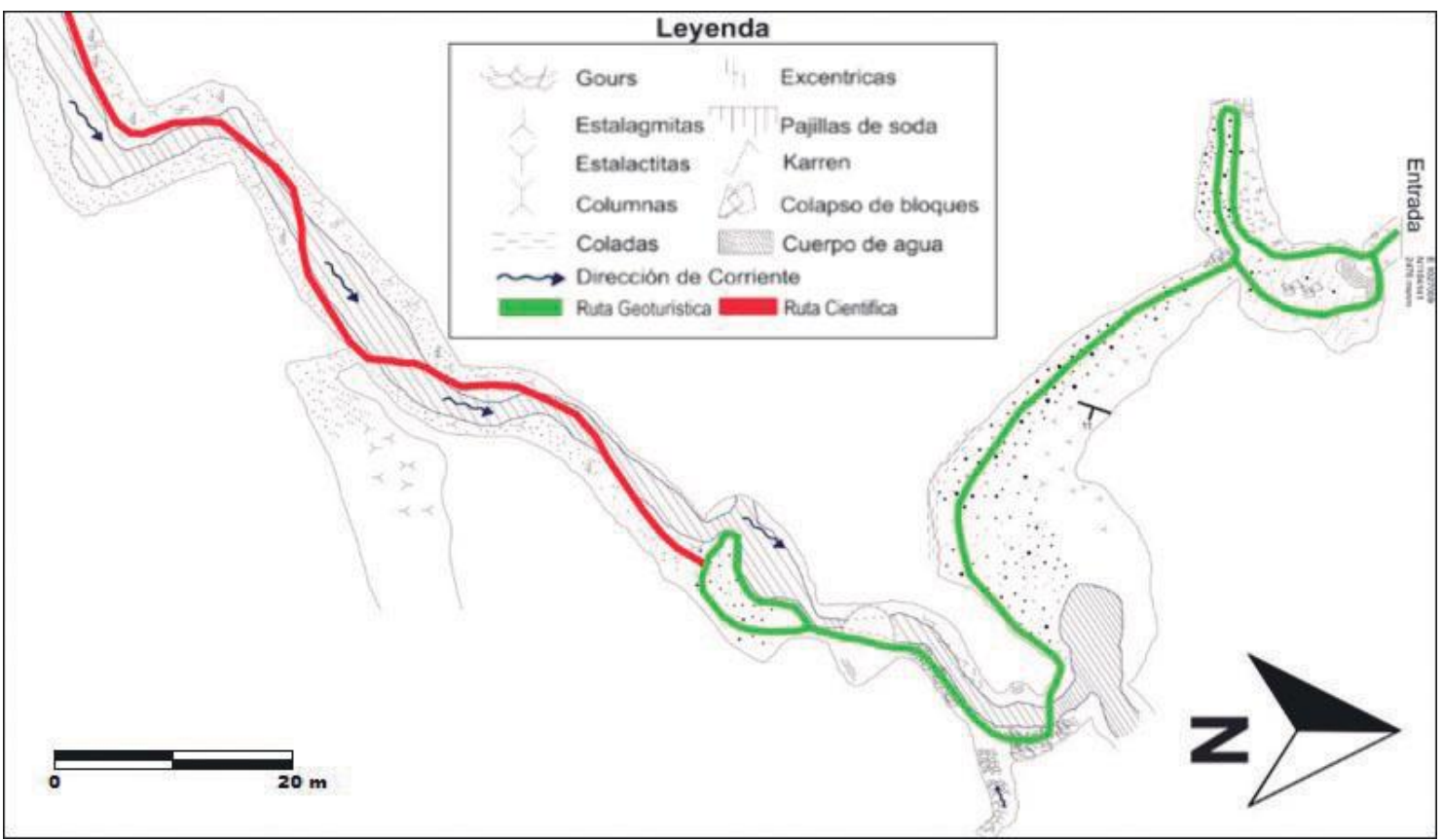

Figura 8. Mapa de la Cueva del Oro.

Hay gran cantidad y variedad de espeleotemas durante todo el recorrido, la variedad de las excéntricas no es tan amplia como en la Caverna Los Carracos; con las pajillas de soda hay excéntricas asociadas de composición similar aragonito, aragonito azul en ciertos lugares de la cavidad (Figura 9). Entre las formas de vida que alberga esta cavidad destacan especies de crustáceos que confirman el estado casi prístino de esta cueva, la cual lleva poco tiempo recibiendo turistas principalmente científicos y con pocas visitas durante el año.
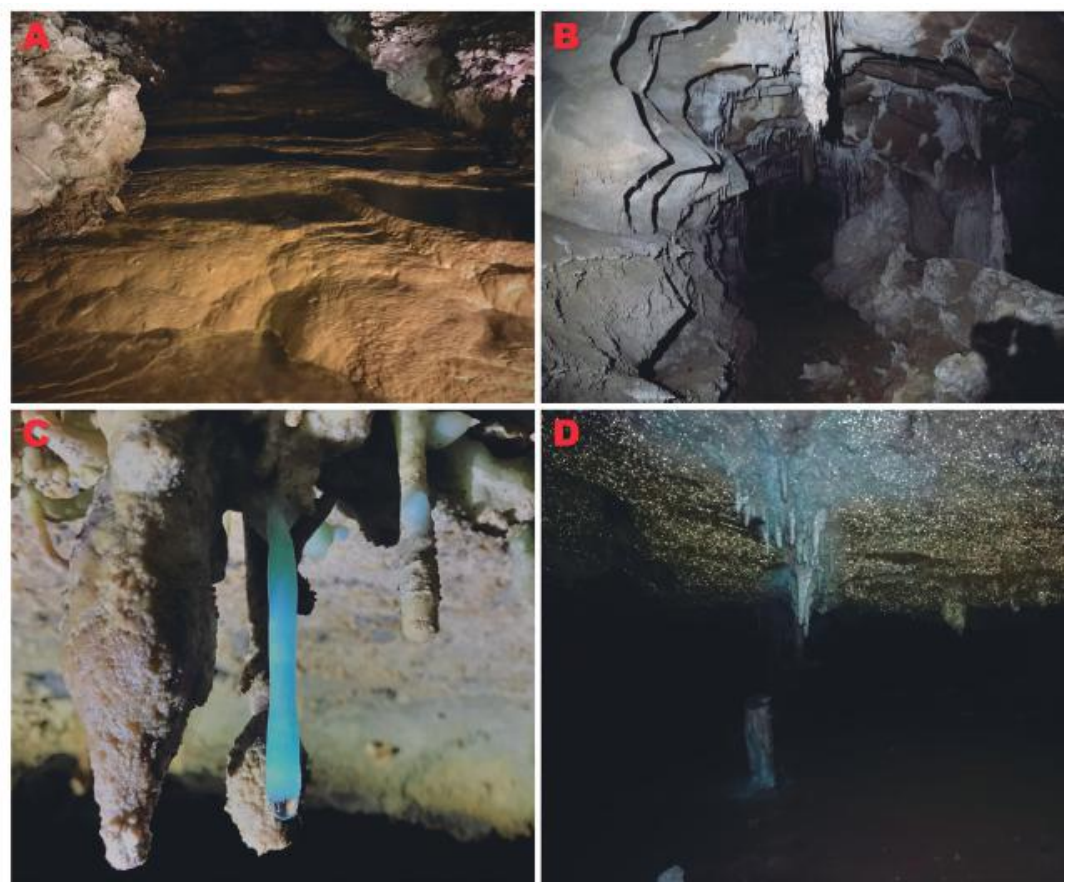

Figura 9. Cueva del Oro: A. Gours y microgours (o "Rimstone Pools"). B. Pasaje de la cavidad evidenciando diferentes variaciones en el nivel freático. C. Estalactitas de Aragonito azules. D. Precipitación de Azufre en el techo de la cavidad. 


\section{Cueva de La Virgen}

La Cueva de La Virgen realmente representa un abrigo rocoso ubicado en cercanías al municipio, sobre la vía El Peñón-Las Cruces. Actualmente constituye un sitio donde algunas personas del municipio y otros municipios vecinos profesan su fe haciendo un acto de peregrinación a esta, principalmente en fechas importantes para la fe católica como la semana santa. Junto a su entrada se encuentra un manantial o fuente kárstica que indica la presencia de un aparato kárstico activo en este macizo, con sus aguas claras también ha constituido un atractivo turístico para algunas de las personas que visitan el lugar. El interés principal de este sitio es el estratigráfico por la exposición de más de 150 m de la Formación Rosablanca (Gómez et $a l ., 2008)$, junto al interés hidrogeológico debido a las surgencias de agua que posee el macizo dando indicios de una circulación de caudal amplia con posible uso potable facilitando una de las necesidades básicas para la comunidad rural.

Un aspecto para tener en cuenta para la gestión integral de este geotopo, es su actual uso para la ganadería (Figura 10), lo que constituye una grave amenaza para la buena calidad del agua que por allí fluye, sin tener en cuenta el incremento en la magnitud de los procesos erosivos que esta actividad económica pueda causar sobre el terreno.
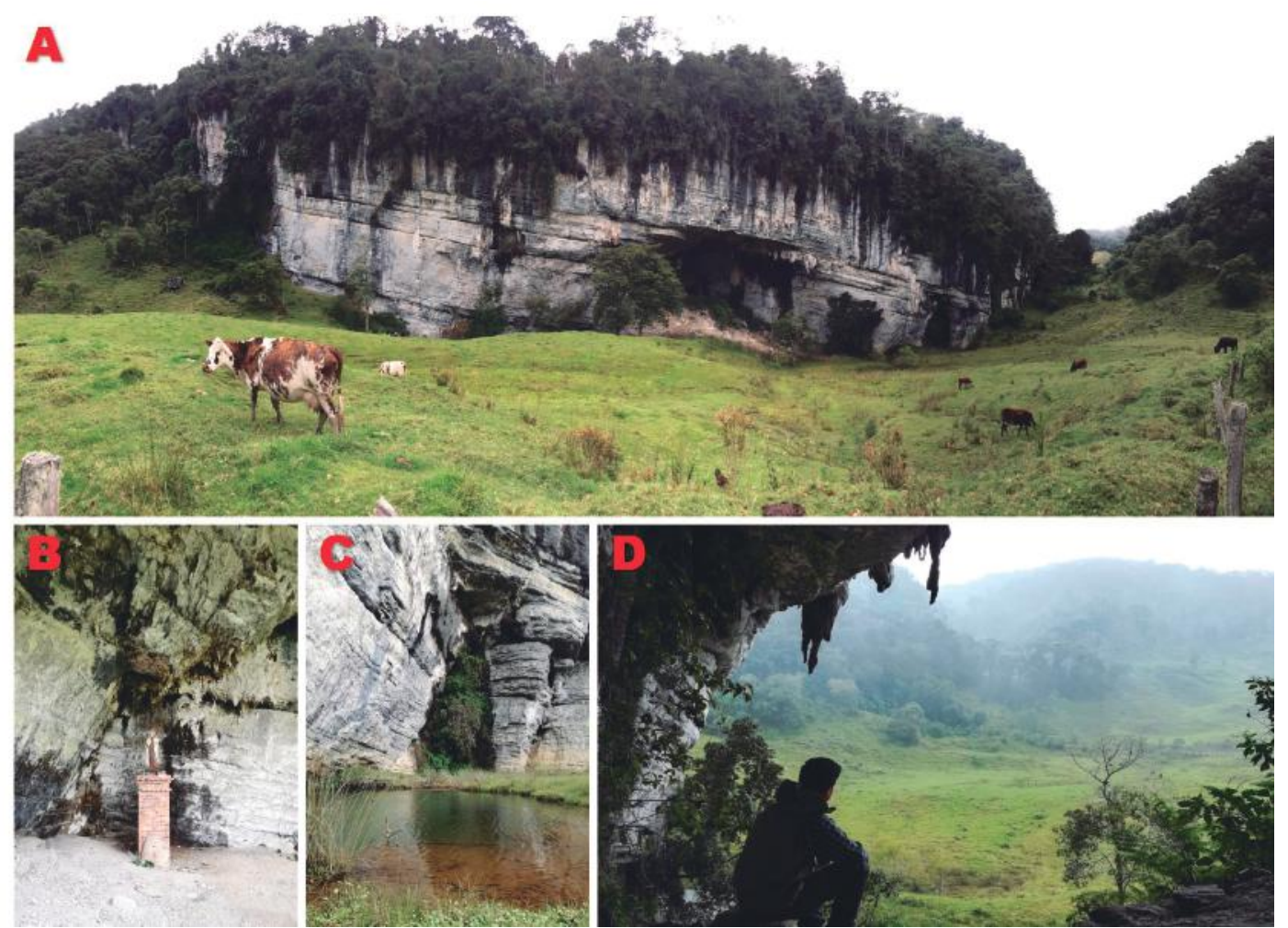

Figura 10. Geotopo "Cueva de La Virgen". A. Escarpe donde se genera el abrigo rocoso. B. Altar a la Virgen dentro de la gruta. C. Surgencia de agua a un costado del escarpe. D. Vista desde el abrigo rocoso.

\section{$\underline{\text { Karst Town }}$}

Karst Town es un campo con gran desarrollo de lapiaces y dolinas, ubicado en cercanías al municipio sobre la vía El Peñón - La Hermosura. Cuenta con una extensión de cerca de $3 \mathrm{~km}^{2}$, donde el atractivo paisajístico es dado por las distintas formas esculturales de karren que se pueden encontrar, con algunas expresiones de hasta $6 \mathrm{~m}$ de altura. El desarrollo de los campos de lapiaces por la ladera del valle de dolinas asemeja a una ciudadela de roca un poco laberíntica dándole un atractivo paisajístico muy alto. En la roca expuesta en los lapiaces algunos estratos tienen contenido fosilífero como bivalvos, gasterópodos y equinodermos (Figura 11). La accesibilidad, visibilidad, y tamaño de este geotopo son ventajas muy marcadas para apreciar todos los rasgos de interés que este presenta. 

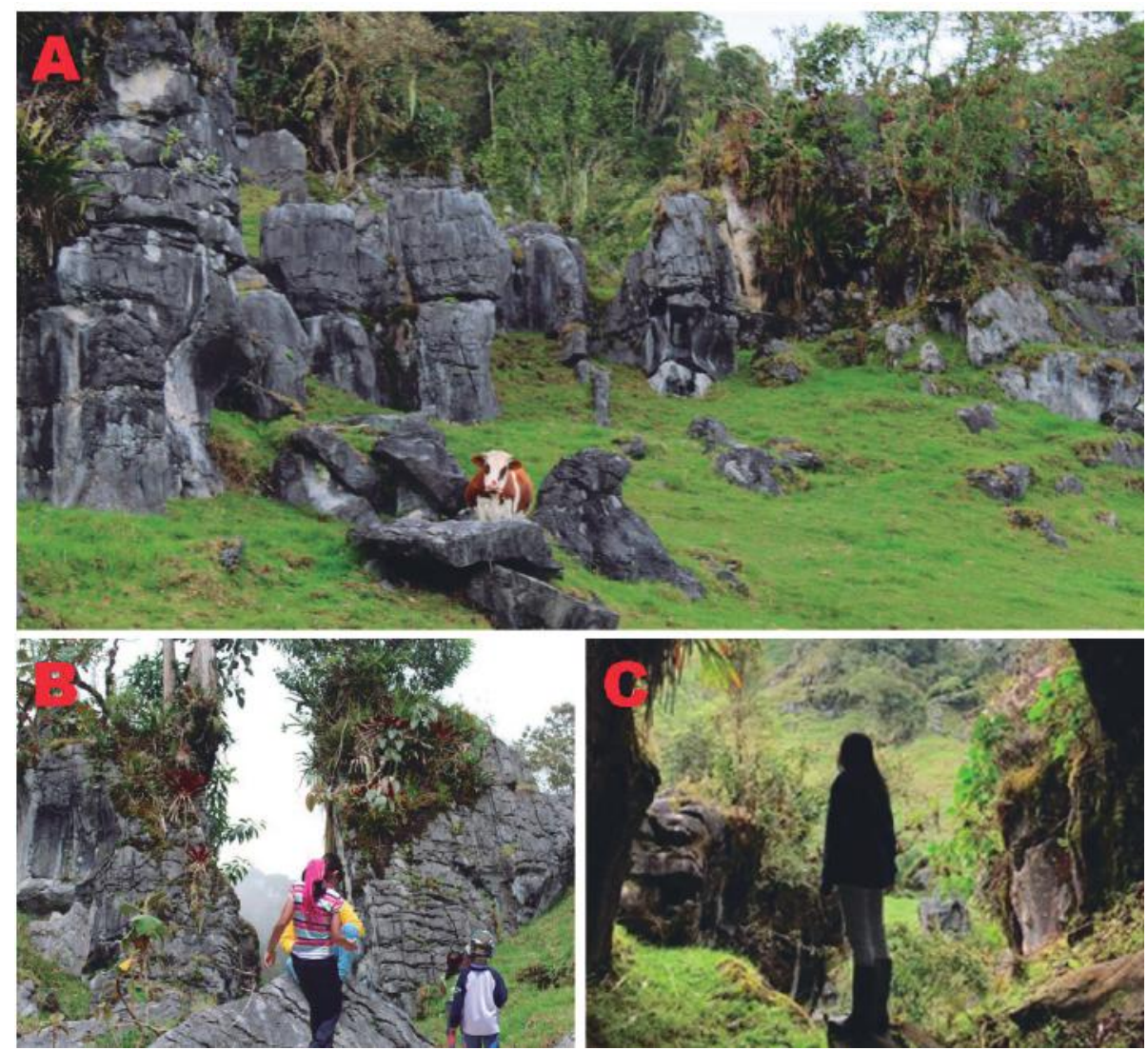

Figura 11. Karst Town. A. Paisaje de meso y mega karren. B. Gasteropodos y bivalvos en los lapiaces. C. Atractivo paisajístico.

\section{Cañón de Panamá}

El Cañón de Panamá es un mirador único que estratigráficamente se encuentra sobre cuarzoarenitas de grano medio a fino intercaladas con capas de lodolitas verdosas. En estas litologías se encuentran venas con drusas de cuarzo de hasta $15 \mathrm{~cm}$ que pueden ser observadas con facilidad en cercanías al mirador. Su interés principal es el geomorfológico debido a la variedad de expresiones geomorfológicas (estructurales, kársticas, denudacionales) que se pueden observar en este sector (Figura 12). Además, tiene intereses secundarios: el tectónico por la claridad con la que se pueden observar estructuras plegadas, mineralógico por la abundancia y belleza de las drusas de cuarzo que se pueden encontrar en el sector, e hidrogeológico por la abundancia del recurso hídrico con la que cuenta el sector.
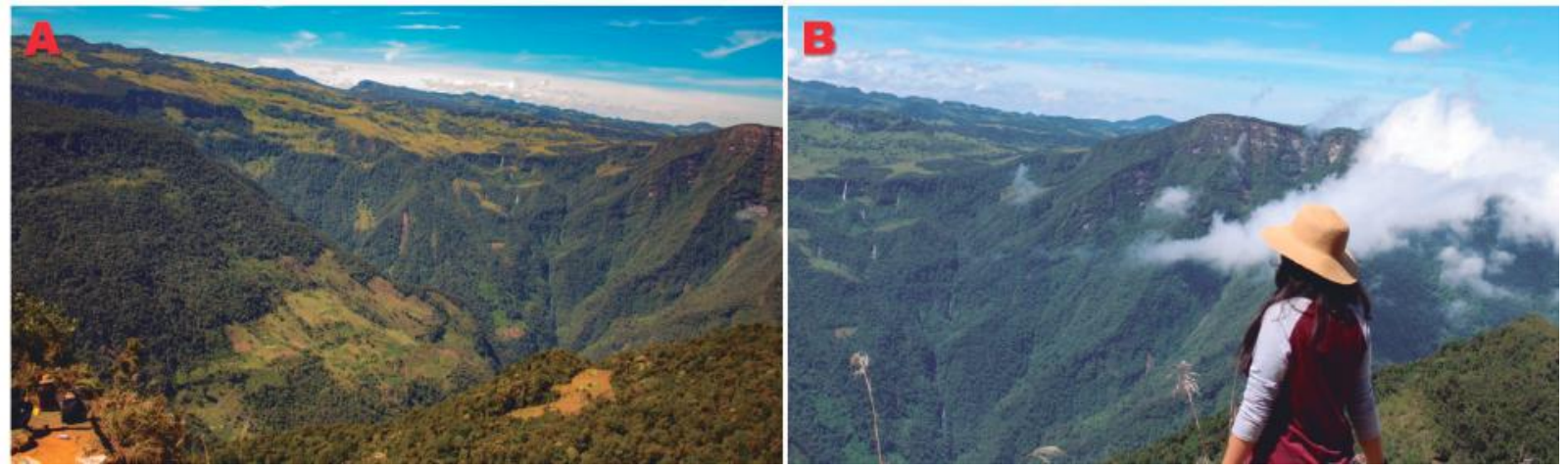

Figura 12. Cañón de Panamá. A. Cascadas y pliegues notorios. B. Cascada con cerca de siete caídas, las "siete maravillas". 


\section{Valoración de Geotopos}

En la Tabla 5 se presentan los valores asignados para cada uno de los subindicadores del método de evaluación y el cálculo para cada geotopo. A pesar de no tener una oferta de geoturismo especializada ni una promoción adecuada, los geotopos valorados presentan valores similares a geositios kársticos con infraestructura y gran afluencia de turistas anualmente de Europa (e.g. Vuković y Antić, 2019).

Tabla 5. Valores dados para cada subindicador e Im. GT1: Caverna Los Carracos. GT2: Caverna La Tronera. GT3: Cueva del Oro. GT4: Cueva de La Virgen. GT5: Karst Town. GT6: Cañón de Panamá.

\begin{tabular}{|c|c|c|c|c|c|c|c|c|c|c|c|c|c|}
\hline \multirow{2}{*}{ Indicadores } & \multicolumn{6}{|c|}{ Valores } & \multirow[t]{2}{*}{ Im } & \multicolumn{6}{|c|}{ Valores Totales } \\
\hline & $\mathrm{GT}_{1}$ & $\mathbf{G T}_{2}$ & $\mathbf{G T}_{3}$ & $\mathbf{G T}_{4}$ & $\mathbf{G T}_{5}$ & $\mathbf{G T}_{6}$ & & $\mathrm{GT}_{1}$ & $\mathrm{GT}_{2}$ & $\mathbf{G T}_{3}$ & $\mathbf{G T}_{4}$ & $\mathbf{G T}_{5}$ & $\mathbf{G T}_{6}$ \\
\hline 1 & 0,25 & 0,25 & 0,25 & 0,25 & 0,25 & 0,25 & 0,9 & 0,225 & 0,225 & 0,225 & 0,225 & 0,225 & 0,225 \\
\hline 2 & 1 & 1 & 1 & 1 & 1 & 0,75 & 0,8 & 0,8 & 0,8 & 0,8 & 0,8 & 0,8 & 0,6 \\
\hline 3 & 1 & 1 & 0,75 & 0,75 & 0 & 0 & 0,4 & 0,4 & 0,4 & 0,3 & 0,3 & 0 & 0 \\
\hline 4 & 1 & 1 & 1 & 1 & 1 & 0,75 & 0,9 & 0,9 & 0,9 & 0,9 & 0,9 & 0,9 & 0,675 \\
\hline 5 & 0,25 & 0,25 & 0,25 & 0,5 & 0,75 & 0,5 & 0,6 & 0,15 & 0,15 & 0,15 & 0,3 & 0,45 & 0,3 \\
\hline 6 & 1 & 1 & 0,5 & 0,5 & 1 & 0 & 0,6 & 0,6 & 0,6 & 0,3 & 0,3 & 0,6 & 0 \\
\hline 7 & 1 & 1 & 1 & 1 & 1 & 0,75 & 0,9 & 0,9 & 0,9 & 0,9 & 0,9 & 0,9 & 0,675 \\
\hline 8 & 1 & 1 & 1 & 0,5 & 0,5 & 1 & 0,7 & 0,7 & 0,7 & 0,7 & 0,35 & 0,35 & 0,7 \\
\hline 9 & 0,75 & 1 & 1 & 1 & 1 & 1 & 0,9 & 0,675 & 0,9 & 0,9 & 0,9 & 0,9 & 0,9 \\
\hline 10 & 0,25 & 0,25 & 0,25 & 0,25 & 0,25 & 0,25 & 0,5 & 0,125 & 0,125 & 0,125 & 0,125 & 0,125 & 0,125 \\
\hline 11 & 0,5 & 0,5 & 0,25 & 0,5 & 0,5 & 0,5 & 0,6 & 0,3 & 0,3 & 0,15 & 0,3 & 0,3 & 0,3 \\
\hline 12 & 0,25 & 0,75 & 0,25 & 0,75 & 1 & 0,5 & 0,4 & 0,1 & 0,3 & 0,1 & 0,3 & 0,4 & 0,2 \\
\hline 13 & 0,25 & 0,25 & 0,25 & 0,75 & 0,75 & 0,5 & 0,7 & 0,175 & 0,175 & 0,175 & 0,525 & 0,525 & 0,35 \\
\hline 14 & 0,5 & 0,5 & 0,5 & 0,5 & 0,5 & 0,5 & 0,6 & 0,3 & 0,3 & 0,3 & 0,3 & 0,3 & 0,3 \\
\hline 15 & 0,25 & 0,25 & 0,25 & 0,25 & 0,25 & 0,25 & 0,4 & 0,1 & 0,1 & 0,1 & 0,1 & 0,1 & 0,1 \\
\hline 16 & 0,5 & 0,5 & 0,5 & 0,5 & 0,5 & 0,5 & 0,5 & 0,25 & 0,25 & 0,25 & 0,25 & 0,25 & 0,25 \\
\hline 17 & 0,5 & 0,5 & 0,5 & 0,5 & 0,5 & 0,5 & 0,6 & 0,3 & 0,3 & 0,3 & 0,3 & 0,3 & 0,3 \\
\hline 18 & 0 & 0 & 0 & 0 & 0 & 0 & 0,5 & 0 & 0 & 0 & 0 & 0 & 0 \\
\hline 19 & 1 & 1 & 0,5 & 0,5 & 0 & 0,5 & 0,7 & 0,7 & 0,7 & 0,35 & 0,35 & 0 & 0,35 \\
\hline 20 & 0,25 & 0,25 & 0,25 & 0,25 & 0,25 & 0,25 & 0,4 & 0,1 & 0,1 & 0,1 & 0,1 & 0,1 & 0,1 \\
\hline 21 & 0,75 & 0,5 & 0,75 & 0,75 & 0,75 & 0,75 & 0,6 & 0,45 & 0,3 & 0,45 & 0,45 & 0,45 & 0,45 \\
\hline 22 & 0 & 0 & 0 & 0 & 0 & 0 & 0,8 & 0 & 0 & 0 & 0 & 0 & 0 \\
\hline 23 & 0,25 & 0,25 & 0,25 & 0,25 & 0,25 & 0,25 & 0,4 & 0,1 & 0,1 & 0,1 & 0,1 & 0,1 & 0,1 \\
\hline 24 & 0 & 0 & 0 & 0 & 0 & 0 & 0,8 & 0 & 0 & 0 & 0 & 0 & 0 \\
\hline 25 & 0,75 & 0,75 & 0,75 & 0,75 & 0,75 & 0,75 & 0,8 & 0,6 & 0,6 & 0,6 & 0,6 & 0,6 & 0,6 \\
\hline 26 & 0,75 & 0,75 & 0,75 & 1 & 0,75 & 0,75 & 0,9 & 0,675 & 0,675 & 0,675 & 0,9 & 0,675 & 0,675 \\
\hline 27 & 0,5 & 0,5 & 0,5 & 0,75 & 0,5 & 0,75 & 0,8 & 0,4 & 0,4 & 0,4 & 0,6 & 0,4 & 0,6 \\
\hline
\end{tabular}




\section{Discusión}

De acuerdo con los subindicadores del valor científico/ educacional, la rareza de todos los geotopos fue evaluada con un puntaje de 0,25 , estos tipos de paisajes kársticos son comunes a nivel regional, pero algunas de sus geoformas endokársticas no son tan comúnes (espeleotemas, simas). Para la representatividad en cambio se obtuvieron valores de 1, exceptuando al Cañón de Panamá con 0,75 , debido a que sus características didácticas, explicativas y de interpretación de eventos geológicos y geomorfológicos son menores si las comparamos con los sistemas subterráneos, que funcionan como laboratorios naturales para la enseñanza de las ciencias de la Tierra. Adicionalmente, las cavernas de Los Carracos y La Tronera son reconocidas a nivel nacional e internacional, por su exuberante belleza, los diversos trabajos científicos realizados y reportes de hallazgos paleontológicos recientes.

Del valor escénico/estético los geotopos obtuvieron puntajes altos en la presencia de paisaje circundante y naturaleza, ya que las cavernas se encuentran rodeadas de vegetación, con presencia de actividad hídrica y poco deterioro inducido por el hombre, la adaptación ambiental de los sitios es alta para las cavernas y el Cañón de Panamá, pero baja para la Cueva de La Virgen y Karst Town.
Los geotopos son protegidos por la comunidad local, se encuentran actualmente en muy buen estado de conservación, exceptuando la Caverna Los Carracos con algunos ligeros daños en su primer nivel, siendo la más visitada de la región. El nivel de vulnerabilidad es medio $(0,5)$, en general, la Caverna Los Carracos y la Cueva del Oro se catalogan como considerablemente sensibles a la degradación antrópica (Tabla 6), por lo que el ingreso de visitantes a estos geotopos debe ser controlado por los guías geoturísticos del sector y no exceder la capacidad de carga de los mismos, ni de las rutas que ya se han planteado para las distintas formas de espeleoturismo que se pueden dar en los mismos (Barajas-Rangel y Gelvez-Chaparro, 2019). Por otro lado, la Caverna La Tronera presenta un grado menor de sensibilidad, y por sus condiciones espeleométricas es la que podría recibir una mayor cantidad de visitantes que pueden acceder por su entrada horizontal o vertical.

Los puntajes obtenidos en la evaluación de valores funcionales (Fn) y turísticos (Tr) son bajos en promedio, y están relacionados con la ausencia de infraestructura tanto en el municipio como en los geotopos, así como su difícil accesibilidad debido a las malas condiciones de las vías locales, lo cual afecta en gran parte la puntuación de los demás subindicadores. Sin embargo, cabe resaltar la oferta de guías turísticos capacitados para la conducción en recorridos por cavernas y su promoción a nivel internacional.

Tabla 6. Resultados de las cuevas analizadas bajo la M-GAM y el Índice de Sensibilidad de Cuevas (CSI).

\begin{tabular}{ccccc}
\hline Geotopo & $\sum$ VP & $\sum$ VA & Campo & CSI \\
\hline Caverna Los Carracos & 5,875 & 4,55 & $\mathrm{Z}_{21}$ & 0,67 \\
Caverna La Tronera & 6,3 & 4 & $\mathrm{Z}_{21}$ & 0,61 \\
Cueva del Oro & 5,55 & 3,8 & $\mathrm{Z}_{21}$ & 0,55 \\
Cueva de La Virgen & 5,7 & 4,575 & $\mathrm{Z}_{21}$ & N.A \\
Karst Town & 5,95 & 3,8 & $\mathrm{Z}_{21}$ & N.A \\
Cañón de Panamá & 4,7 & 4,175 & $\mathrm{Z}_{21}$ & N.A \\
\hline
\end{tabular}

Se destaca que con los resultados descritos anteriormente todos los geotopos caen en el campo $\mathrm{Z}_{21}$ (Figura 13), indicando importantes valores principales pero bajos a muy bajos valores adicionales. El estado casi prístino de los geotopos, el desarrollo de variadas e importantes investigaciones en la zona, la gran belleza y estado de conservación de las geoformas endokársticas al ser comparadas con otros sistemas kársticos del país da importantes valores científicoseducativos, estéticos y de protección a la mayoría de estos sitios. 


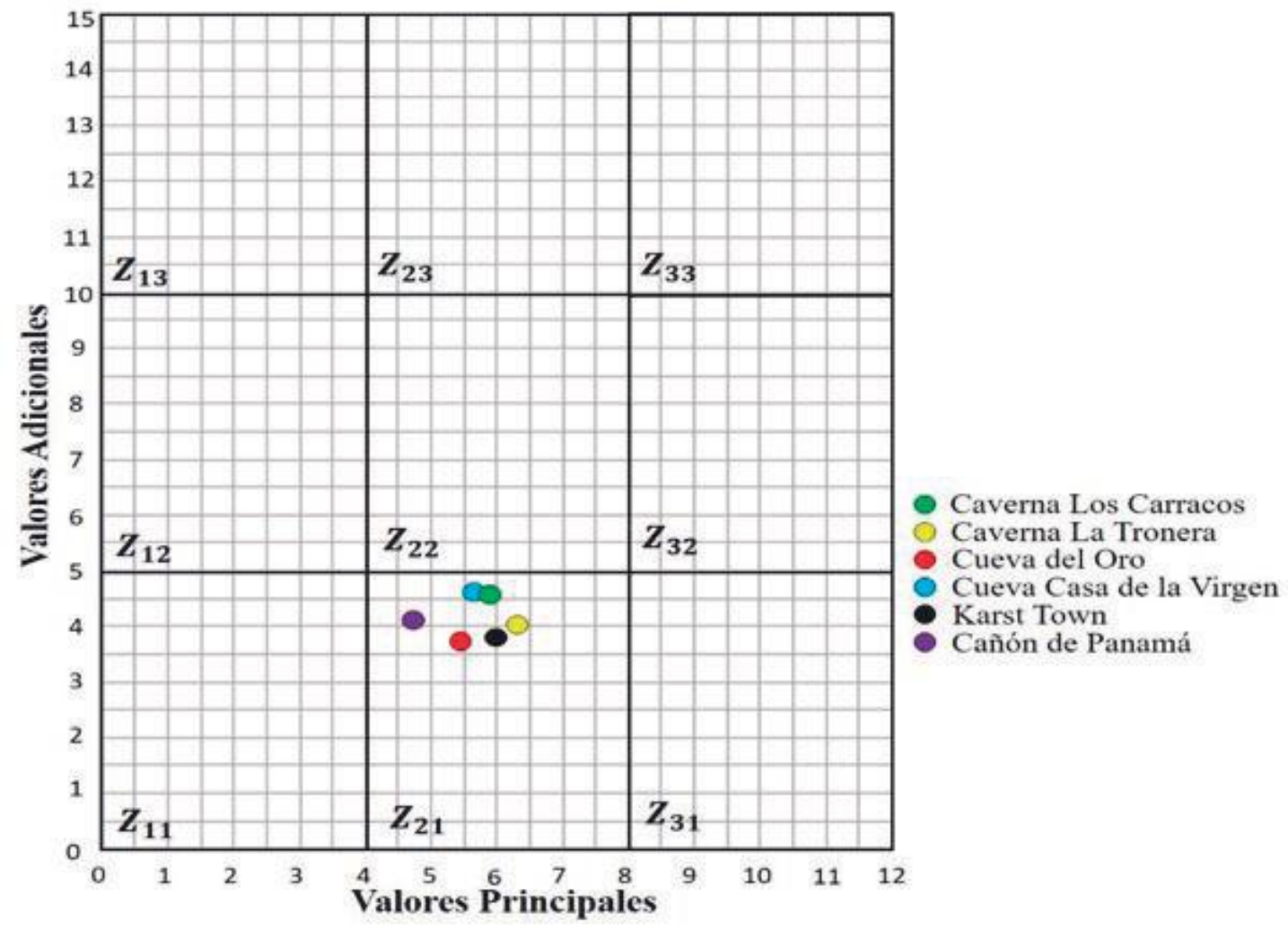

Figura 13. Posición de los geotopos evaluados en la matriz de M-GAM.

\section{Conclusiones}

El evidente desarrollo kárstico en la región de El Peñón está controlado principalmente por la geología estructural de la zona, evidenciado en las orientaciones preferenciales dadas por las fracturas tensionales NW-SE y NE-SW que adquieren las unidades exo y endokársticas; si bien debido a este control tectónico se desarrollan cavidades en la mayoría de niveles de la Formación Rosablanca, la composición química de esta juega un papel importante en el desarrollo de las variedades y cantidades de espeleotemas presentes en algunas cuevas o cavernas, incluso las anomalías de sulfuros presentes en la roca son evidenciadas en las precipitaciones y/o clastos encontrados dentro del sistema kárstico.

El turismo en sistemas kársticos ha dejado grandes beneficios en el desarrollo de comunidades y la conservación de su patrimonio en las diferentes partes del mundo donde ha sido aplicado de manera correcta. Los geotopos aquí mencionados son propuestos para la implementación de prácticas de Geoturismo y Espeleoturismo que logren aprovechar todo su potencial, generando conciencia geológica y de protección ambiental en todos sus visitantes.
La mejora en la infraestructura de transporte, comunal y turística es necesaria para un mayor desarrollo turístico, que a su vez impacte en el desarrollo de la economía local y regional.

Es necesario el diseño e instalación de paneles explicativos en cada uno de los geotopos que destaque los rasgos y procesos sobresalientes en cada uno de ellos, el mal estado de las vías de acceso ha contribuido a la conservación de varios de los geotopos pero es necesario su mejoramiento para la afluencia de un mayor número de visitantes, así como la habilitación de senderos que procuren por un turismo inclusivo y causen el menor impacto ambiental; de igual manera se recomienda en la Caverna La Tronera el análisis de factibilidad para la construcción de una plataforma que facilite el ingreso a los visitantes por la entrada horizontal.

La galería inferior de la Caverna Los Carracos presenta una alta diversidad geológica y un alto valor científico, además de ser considerablemente sensible a perturbaciones antrópicas, por lo que se recomienda sea destinada principalmente para turismo científico y didáctico que pretenda ahondar en las distintas ramas de las ciencias del Karst y aportar nuevos datos de 
este sistema (bioespeleología, paleoclimatología, hidrogeología, mineralogía, tectónica).

Es indispensable el trabajo social con las comunidades, especialmente en la zona rural con los propietarios de los predios en donde hay manifestaciones subterráneas y potenciales geotopos. La instalación de equipos en las cavidades subterráneas para su constante monitoreo, junto al trabajo y comunicación constante con las comunidades garantizará el monitoreo y preservación del patrimonio natural del territorio.

\section{Agradecimientos}

Los autores agradecen a Ferney Vásquez, por su guianza en las expediciones espeleológicas, las útiles discusiones y comentarios que contribuyeron al desarrollo de este trabajo. Así mismo agradecen a los miembros del Grupo de Geoespeleología de la Universidad Industrial de Santander por su acompañamiento en las campañas de campo y formación en ciencias del Karst.

\section{Referencias}

Antić, A.; Tomić, N. (2017). Geoheritage and geotourism potential of the Homolje area (eastern Serbia). Acta Geoturistica, 8(2), 67-78. doi: 10.1515/agta-2017-0007

Antić, A.; Tomić, N.; Marković, S. (2019). Karst geoheritage and geotourism potential in the Pek River lower basin (eastern Serbia). Geographica Pannonica, 23(1), 32-46. doi: 10.5937/gp2320463

Barajas-Rangel, D.; Gelvez-Chaparro, J. (2019). Geoespeleología y Geoturismo en Cavernas de El Peñón (Santander): Conocimiento y alternativas para la Geoconservación de Sistemas Kársticos. Tesis, Universidad Industrial de Santander, Bucaramanga, Colombia.

Božić, S.; Tomić, N. (2015). Canyons and gorges as potential geotourism destinations in Serbia: Comparative analysis from two perspectives general geotourists' and pure geotourists'. Open Geosciences, 7(1), 531-546. doi: 10.1515/geo2015-0040
Campos, M.; Acevedo, A.; Lasso, C.; FernándezAuderset, J. (2018). Variaciones morfológicas y algunas notas bioecológicas del cangrejo de agua dulce Neostrengeria charalensis Campos y Rodríguez, 1985 (Decapoda: Pseudothelphusidae), en ambientes exo y endocársticos de los Andes colombianos. Biota Colombiana, 19(Sup. 1), 6583. doi: 10.21068/c2018.v19s1a07

Carcavilla, L.; Belmonte, Á.; Durán, J.J.; LópezMartínez, J.; Robledo, P.A. (2016). Patrimonio geológico y geodiversidad en terrenos kársticos en España. Enseñanza de las Ciencias de la Tierra, 24(1), 61-73.

Carcavilla-Urquí, L.; López-Martínez, J.; DuránValsero, J.J. (2007). Patrimonio geológico y geodiversidad: investigación, conservación, gestión y relación con los espacios naturales protegidos. Madrid: Instituto Geológico y Minero de España, Serie Cuadernos del Museo Geominero, n.7.

Cigna, A.; Forti, P. (2013). Caves: the most important geotouristic feature in the world. Tourism and Karst Areas, 6(1) 9-26.

Colegial, J.D.; Pisciotti, G.; Uribe, E. (2002). Metodología para la definición, evaluación y valoración del patrimonio geológico y su aplicación en la geomorfología glaciar de Santander (municipio de Vetas). Boletín de Geología, 24(39), 121-134.

Figueiredo, L.A. (2014). Espeleoturismo, educación ambiental y procesos formativos de espeleología: reporte de experiencias en Brasil y México. VII Congreso de Espeleología de América Latina y del Caribe, Catacamas, Honduras.

Galvis-Gómez, M.A. (2018). Mapa del potencial kárstico del departamento de Santander (Colombia). Tesis de Especialización, Universidad Militar Nueva Granada, Bogotá, Colombia.

Gelvez-Chaparro, J.; Herrera-Ruiz, J.; Zafra-Otero, D.; Barajas-Rangel, D.; Díaz-Carreño, J.; RíosReyes, C. (2018). Geotouristic potential in karst systems of Santander (Colombia): the beginning of right geoeducational and geoconservational practices. International Journal of Hydrology, 2(6), 713-716. doi: 10.15406/ijh.2018.02.00148 
Gómez, A. (1977). Fotogeología de la zona BarbosaLandázuri. Boletín de Geología, 11(25), 99-106.

Gómez, L.; Lancheros, J.; López, C.; Patiño, A.; Beltran, A.; Renzoni, G.; Guerra, A.; Quintero, C. (2008). Cartografía geológica y muestreo geoquímico escala 1:100.000 de la plancha 150, Cimitarra. Valle Medio del Magdalena. INGEOMINAS.

Gunn, J. (2004). Encyclopedia of Cave and Karst Science. New York: Fitzroy Dearborn.

Hapka, R.; Jutzet, J.M.; Bochud, M.; Fernandez, J. (2015). Speleo-Colombia 2011-2013. Cavernes, Special Colombie, 5-95.

Harley, G.L.; Polk, J.S.; North, L.A.; Reeder, P.P. (2011). Application of a cave inventory system to stimulate development of management strategies: the case of west-central Florida, USA. Journal of Environmental Management, 92(10), 2547-2557. doi: 10.1016/j.jenvman.2011.05.020

Julivert, M. (1968). Lexique Stratigraphique International. Vol. V Amerique Latine, Fasc. 4. Colombie. Paris: Centre National de la Recherche Scientifique.

Llopis-Lladó, N. (1970). Fundamentos de hidrogeología cárstica. Introducción a la geoespeleología. Barcelona: Editorial Blume.

Mantilla-Figueroa, L.C.; Cruz, L.E.; Colegial, J.D. (2003). Introducción a la geología del sector Vélez-Bolívar-Guavatá (Dpto. de Santander, Colombia) y su importancia para la exploración de depósitos hidrotermales. Boletín de Geología, 25(40), 39-57.

Mendoza-Parada, J.E.; Moreno-Murillo, J.M.; Rodríguez-Orjuela, G. (2009). Sistema Cárstico de la Formación Rosablanca Cretácico inferior, en la provincia santandereana de Vélez, Colombia. Geología Colombiana, 34, 35-44.

Muñoz-Saba, Y.; Andrade, G.; Baptiste, L.G.; Salas, D.; Villareal, H.; Armenteras, D. (1998). Conservación de los ecosistemas subterráneos en Colombia. Biosintesis, 10, 1-4.

Newsome, D.; Dowling, R. (2018). Geoheritage and geotourism. In: E. Reynard; J. Brilha (eds.).
Geoheritage: assessment, protection, and management (pp. 305-321). Chapter 17. Elsevier Inc.

Núñez, A. (1970). Clasificación genética de las cuevas de Cuba. Serie espeleológica y Carsológica, No 7. Simposio XXX Aniversario Sociedad Espeleológica de Cuba, La Habana, Cuba.

Palacio-Prieto, J.L.; Sanchez-Cortez, J.L.; Schilling, M.E. (2016). Patrimonio geológico y su conservación en América Latina. Situación y perspectivas nacionales. Ciudad de México: Instituto de Geografía, Universidad Nacional Autónoma de México.

Ramirez-Ruiz, V.M. (2014). Reconstituição Paleoclimática dos últimos 5.500 anos nos Andes Orientais da Colômbia. Dissertacao de Mestrado. Universidade de Sao Paulo, Brasil. doi: 10.11606/D.44.2014.tde-03122014-093609

Šuleić, M.; Pavić, D. (2016). Gorges as potential geotourism attractions of Serbia - comparative analysis of Ovčarsko - Kablarska Gorge and Grdelička Gorge by using M-GAM Model. Acta Geoturistica, 7(1), 10-20.

Tomić, N.; Božić, S. (2014). A Modified Geosite Assessment Model (M-GAM) and its application on the Lazar Canyon area (Serbia). International Journal of Environmental Research, 8(4), 10411052. doi: $10.22059 /$ ijer.2014.798

Tomić, N.; Marković, S.; Korać, M.; Mrdić, N.; Hose, T.; Vasiljević, D.; Jovićić, M.; Gavrilov, M. (2015). Exposing mammoths: From loess research discovery to public palaentological park. Quaternary International, 372, 142-150. doi: 10.1016/j.quaint.2014.12.026

Vujičić, M.D.; Vasiljević, D.A.; Marković, S.B.; Hose, T.A.; Lukić, T.; Hadžić, O.; Janićević, S. (2011). Preliminary geosite assessment model (GAM) and its application on Fruška Gora Mountain, potential geotourism destination of Serbia. Acta Geographica Slovenica, 51(2), 361-376. doi: 10.3986/AGS51303

Vuković, S.; Antić, A. (2019). Speleological approach for geotourism development in Zlatibor county (West Serbia). Turizam, 23(1), 53-68. doi: 10.5937/turizam23-21325 


\begin{tabular}{c}
\hline \hline Jorge Gelvez-Chaparro \\
ORCID: 0000-0002-4327-1367 \\
Daniel Barajas-Rangel \\
ORCID: 0000-0003-0238-8494 \\
Juliana Herrera-Ruiz \\
ORCID: 0000-0003-3476-4191 \\
Carlos Alberto Ríos-Reyes \\
ORCID: 0000-0002-3508-0771 \\
\hline \hline
\end{tabular}

Trabajo recibido: noviembre 02 de 2019

Trabajo aceptado: abril 23 de 2020 